\title{
Modulation of mitochondrial DNA copy number in a model of glioblastoma induces changes to DNA methylation and gene expression of the nuclear genome in tumours
}

\author{
Xin Sun ${ }^{1,2}$ and Justin C. St John ${ }^{1,2^{*}}$ (B)
}

\begin{abstract}
Background: There are multiple copies of mitochondrial DNA (mtDNA) present in each cell type, and they are strictly regulated in a cell-specific manner by a group of nuclear-encoded mtDNA-specific replication factors. This strict regulation of mtDNA copy number is mediated by cell-specific DNA methylation of these replication factors. Glioblastoma multiforme, HSR-GBM1, cells are hyper-methylated and maintain low mtDNA copy number to support their tumorigenic status. We have previously shown that when HSR-GBM1 cells with $50 \%$ of their original mtDNA content were inoculated into mice, tumours grew more aggressively than non-depleted cells. However, when the cells possessed only $3 \%$ and $0.2 \%$ of their original mtDNA content, tumour formation was less frequent and the initiation of tumorigenesis was significantly delayed. Importantly, the process of tumorigenesis was dependent on mtDNA copy number being restored to pre-depletion levels.

Results: By performing whole genome MeDIP-Seq and RNA-Seq on tumours generated from cells possessing 100\%, $50 \%, 0.3 \%$ and $0.2 \%$ of their original mtDNA content, we determined that restoration of mtDNA copy number caused significant changes to both the nuclear methylome and its transcriptome for each tumour type. The affected genes were specifically associated with gene networks and pathways involving behaviour, nervous system development, cell differentiation and regulation of transcription and cellular processes. The mtDNA-specific replication factors were also modulated.
\end{abstract}

Conclusions: Our results highlight the bidirectional control of the nuclear and mitochondrial genomes through modulation of DNA methylation to control mtDNA copy number, which, in turn, modulates nuclear gene expression during tumorigenesis.

Keywords: Mitochondrial DNA, DNA methylation, Gene expression, Tumorigenesis, POLG

\section{Background}

Mammalian cells have multiple copies of the mitochondrial genome (mtDNA) within each mitochondrion. The human mitochondrial genome is a circular, doublestranded genome that is $16.6 \mathrm{~kb}$ in size. It is essential for the production of cellular ATP, as it encodes 13 subunits

\footnotetext{
*Correspondence: Justin.StJohn@hudson.org.au

1 Mitochondrial Genetics Group, Hudson Institute of Medical Research,

27-31 Wright Street, Clayton, VIC 3168, Australia

Full list of author information is available at the end of the article
}

of the electron transfer chain that conducts oxidative phosphorylation (OXPHOS) and is the cell's major generator of ATP. It also encodes 22 transfer RNAs and 2 ribosomal RNAs [1].

mtDNA replication is driven by nuclear-encoded mtDNA-specific replication factors that translocate to the mitochondrion. The primary factor is the mtDNAspecific polymerase, polymerase gamma $[2,3]$, which is a heterotrimer enzyme composed of a catalytic subunit, subunit A (POLG), and two supporting subunits, subunits $B$ (POLG2) [4]. The process of mtDNA replication 
is also supported by the mitochondrial helicase twinkle (TWNK), the single-stranded DNA binding protein (SSBP1) and the mitochondrial topoisomerase (TOP1MT) [5-7]. There are several other key factors including mitochondrial transcription factors A (TFAM), B1 (TFB1M) and B2 (TFB2M), which generate the precursor transcript used to initiate mtDNA replication $[8,9]$. Furthermore, some upstream regulators of these mtDNA replication factors are highly involved in mitochondrial biogenesis and function. These include nuclear respiratory factors 1 and 2 (NRF1/2), peroxisome proliferator-activated receptor $\gamma$ (PPARG) and its co-activator PGC1 $\alpha$ (PPARGC1A), the Sirtuin family of genes (SIRT13 ), and the oestrogen-related receptors (ESRRA/B/G) [10-14].

mtDNA replication is strictly regulated during development and differentiation, which enables mature cells to acquire the requisite numbers of mtDNA copy to support their specific functions [15-18]. Initially, this is achieved by pluripotent (naïve) cells having established the mtDNA set point (reviewed in [19]). These naïve cells each possess around 200 copies of mtDNA, which promotes glycolysis as the favoured form of energy production, and cellular proliferation [20]. These copies of mtDNA serve as the initial template for mtDNA replication, allowing cells to acquire the appropriate numbers of mtDNA copy as they differentiate into mature cell types [16-18, 20, 21].

The inability to regulate mtDNA copy number affects cellular function and impedes developmental potential. For example, oocytes at the metaphase II stage that possess too few copies of mtDNA frequently fail to fertilize [22-25]. Likewise, certain types of cancer cells exhibit low mtDNA copy number and are unable to successfully complete differentiation $[16,18]$. Indeed, cancer cells mainly rely on aerobic glycolysis for energy production, which allows for higher rates of cellular proliferation and prevents differentiation from taking place [16]. However, when they are induced to differentiate, they appear to be trapped in a 'pseudo-differentiated' state as they had not previously maintained the mtDNA set point and, as a result, the nuclear and mitochondrial genomes do not act in synchrony $[19,26]$. Interestingly, when cancer cells are partially depleted of their mtDNA content, they undergo dedifferentiation and are then able to replicate mtDNA as they undergo differentiation, suggesting that they have re-established the mtDNA set point and synchrony between the nuclear and mitochondrial genomes [18].

During the early stages of development, the nuclear genome undergoes DNA demethylation mediated by the ten-eleven translocation methylcytosine dioxygenases (TET enzymes) to erase parental DNA methylation profiles. De novo DNA methylation then takes place to establish a new DNA methylation profile directed by the DNA methyltransferase family (DNMTs), which primes naïve cells for cellular differentiation [27, 28]. To this extent, cell-specific gene expression profiles are established during differentiation in synchrony with changes to DNA methylation patterns. Likewise, the DNA methylation status at exon 2 of POLG is a determinant of when this gene is expressed and, in turn, regulates mtDNA copy number in a cell-specific manner [15, 16]. This is supported by experiments using DNA demethylation agents, such as 5-azacytidine [29] and vitamin $C$ [30], where modulation of DNA methylation at exon 2 of $P O L G$ increased mtDNA copy number in HSR-GBM1 cells derived from a glioblastoma multiforme (GBM) tumour $[16,18,31]$.

The HSR-GBM1 cell line is a high-grade malignant GBM cell line that is characterized as being similar to stem-like neural precursors and is extensively DNA methylated, which contributes to its tumorigenic gene profile [32, 33]. However, its hyper-methylated profile is not established by the overexpression of the isocitrate dehydrogenases (IDH1/2) that harbour onco-mutations, as the alleles for these genes are wild type [34, 35]. Under normal circumstances, IDH enzymes act on the citric acid cycle to generate $\alpha$-ketoglutarate, which is a co-factor of the TET enzymes that modulate DNA demethylation patterns [36-40]. However, overexpression of and mutations to the $I D H$ genes in GBM result in a metabolic switch that produces 2-hydroxyglutarate and restricts DNA demethylation induced by the TET enzymes [36-40]. Consequently, HSR-GBM1 cells enable the analysis of modifications to DNA methylation profiles to be undertaken whereby the DNA methylation status of the cells is not influenced by mutations to key regulators of DNA demethylation and thus allows the effects of mtDNA copy number to be studied independently of these influences.

Interestingly, mtDNA depletion of HSR-GBM1 cells to varying amounts of mtDNA copy number affected tumour progression and frequency when these cells were inoculated into mice [18]. Progression and frequency were greatest in cells depleted to $50 \%$ of their original content, but tumour formation was less frequent and took significantly longer when cells possessed only $3 \%$ and $0.2 \%$ of their original mtDNA content [18]. Notably, mtDNA copy was restored to similar levels during in vivo tumorigenesis accompanied by DNA demethylation at exon 2 of POLG [17].

In order to determine whether global DNA methylation profiles were modulated following the restoration and maintenance of mtDNA copy number in end point tumours, we investigated the DNA methylation profiles of GBM tumours derived from HSR-GBM1 cells that 
possessed varying amounts of mtDNA copy number and exhibited different frequencies and progression in tumour formation. We used whole genome methylated DNA immunoprecipitation (MeDIP)-Seq. We matched the modulated regions with their transcriptional profiles to focus on their effects on gene expression. We also investigated the mtDNA replication factors to determine how they responded to the newly established interactions between the nucleus and the mitochondrial genome. Our results highlight the bidirectional control of the nuclear and mitochondrial genomes through modulation of DNA methylation to control mtDNA copy number and gene expression in tumours using the HSR-GBM1 cell line as a model.

\section{Results}

\section{Replenishment of mtDNA copy number}

Tumours were previously generated from HSR-GBM1 cells possessing different levels of mtDNA copy number, namely $\mathrm{GBM}^{100}$ (possessing $100 \%$ of their mtDNA content), $\mathrm{GBM}^{50}$ (50\% mtDNA content), $\mathrm{GBM}^{3}$ (3\% mtDNA content) and $\mathrm{GBM}^{0.2}(0.2 \% \mathrm{mtDNA}$ content) cells [18]. Tumours arising from $\mathrm{GBM}^{3}$ and $\mathrm{GBM}^{0.2}$ cells had significantly delayed initiation and reached end point at 83 and 90 days, respectively. They had a lower frequency of tumour formation (6/12 and 2/12, respectively) compared with $\mathrm{GBM}^{100}$ tumours, which took 65 days to reach end point with tumours forming from 11/12 inoculations [18]. GBM $^{50}$ tumours had accelerated formation (61 days) [18]. Furthermore, mtDNA copy number was replenished in each of the end point tumours to pre-depletion levels without significant differences (Fig. 1), which highlights the need for sufficient mtDNA copy number to promote tumorigenesis, and likely explains why delayed tumour formation was observed in cells with lower levels of mtDNA copy number.

\section{Modifications to DNA methylation resulting from re-establishment of mtDNA copy number during tumorigenesis}

In order to determine whether DNA methylation of the nuclear genome was modulated following re-establishment of mtDNA copy number during tumour progression, we assessed the global DNA methylation profiles of each of the tumour types at end point. Whole genome MeDIP-Seq was performed on DNA extracted from individual tumours from each cohort to identify key regions that might be modulated. Using the MEDIPS package, the quality of the sequencing reads was determined using the saturation and enrichment analyses and each achieved high standards, indicating that there was sufficient coverage and enrichment of the methylated DNA (Additional file 1). Regions with total coverage of

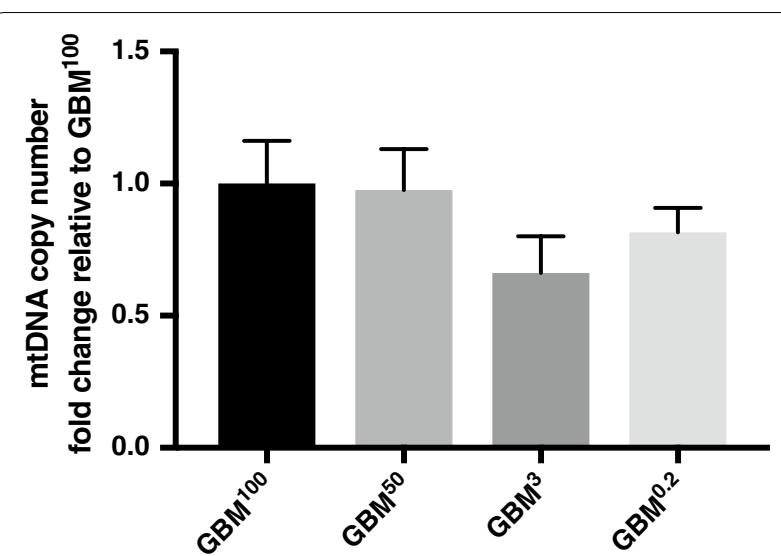

Fig. 1 Replenishment of mtDNA copy number in the $\mathrm{GBM}^{50}, \mathrm{GBM}^{3}$ and $\mathrm{GBM}^{0.2}$ tumours. Fold change in mtDNA copy number for $\mathrm{GBM}^{50}, \mathrm{GBM}^{3}$ and $\mathrm{GBM}^{0.2}$ tumours relative to the $\mathrm{GBM}^{100}$ tumours. $\mathrm{GBM}^{100}, \mathrm{GBM}^{50}, \mathrm{GBM}^{3}$ and $\mathrm{GBM}^{0.2}$ tumours were harvested at 65 days, 61 days, 83 days and 90 days after inoculation, respectively. Statistical significance was determined using one-way ANOVA ( $n=3$ tumours per group; technical triplicates per sample). No significant differences were identified between the groups

$100 \times($ minrowsum $=100)$ or greater reads were used for statistical analysis, which is deemed to be a more stringent filter than the default threshold of tenfold coverage [31].

A common feature of cancer cells is genomic instability, which causes significant copy number variation (CNV) when compared to healthy controls [41]. CNV can also affect the outcomes from comparative analysis after MeDIP-Seq, which, if ignored, can introduce false positive results due to CNVs inducing higher or lower levels of enrichment rather than being reflective of the real differences in DNA methylation [41]. Using the Illumina Global Screening Array, no CNVs were identified to be significantly different between the tumour groups, as assessed using the NEXUS Copy Number Module. This negates the potential effect of $\mathrm{CNV}$ on the analysis of MeDIP-Seq outcomes (see Additional file 2).

Differentially methylated regions (DMRs) were identified between the $\mathrm{GBM}^{100}$ tumours and tumours formed from cells possessing varying levels of mtDNA. Table 1 shows the number of DMRs identified in the $\mathrm{GBM}^{50}$, $\mathrm{GBM}^{3}$ and $\mathrm{GBM}^{0.2}$ tumours when compared with the $\mathrm{GBM}^{100}$ tumours using different filters for statistical significance. With the increase in statistical power ( $p$ value) from $\leq 0.05,0.01$ to 0.001 , fewer DMRs were identified in each comparison. Overall, there were fewer DMRs identified in the $\mathrm{GBM}^{3}$ tumours followed by the $\mathrm{GBM}^{50}$ tumours whilst there were far more DMRs identified in the $\mathrm{GBM}^{0.2}$ tumours. Using a cut-off $p$ value of 0.001 , for instance, 124 DMRs were identified between the 
Table 1 The number of DMRs identified in tumours ( $n=3$ per group) formed from depleted cells compared with nondepleted cells

\begin{tabular}{|c|c|c|c|c|}
\hline Comparisons & $p \leq 0.05$ & $p \leq 0.01$ & $p \leq 0.001$ & Adj. $p \leq 0.05$ \\
\hline $\mathrm{GBM}^{50}$ versus $\mathrm{GBM}^{100}$ & 8980 (16.85\%: 83.15\%) & 1135 (10.57\%: 89.43\%) & 124 (7.26\%: 92.74\%) & - \\
\hline $\mathrm{GBM}^{3}$ versus $\mathrm{GBM}^{100}$ & 4940 (34.76\%: 65.24\%) & 597 (41.88\%: 58.12\%) & 36 (44.44\%: 55.56\%) & - \\
\hline $\mathrm{GBM}^{0.2}$ versus $\mathrm{GBM}^{100}$ & 51,366 (11.25\%: 88.75\%) & 34,060 (3.66\%: 96.34\%) & 16,565 (2.14\%: 97.86\%) & 143 (21.68\%: 78.32\%) \\
\hline
\end{tabular}

The ratio of hyper- and hypo-methylated DMRs (expressed as percentages) is shown in brackets

$\mathrm{GBM}^{50}$ tumours and the $\mathrm{GBM}^{100}$ tumours, 36 DMRs for the $\mathrm{GBM}^{3}$ tumours and 16,565 DMRs for the $\mathrm{GBM}^{0.2}$ tumours. The greater number of DMRs identified for the $\mathrm{GBM}^{0.2}$ tumours indicated that the DNA methylation profile for this cohort of tumours was extensively modified as a result of the increased levels of mtDNA depletion in their initiating cells and subsequent restoration during tumorigenesis. We further applied the Bonferroni correction to adjust $p$ values to control for false positive calls. After correction, there were 143 DMRs identified in the $\mathrm{GBM}^{0.2}$ tumours, but there were no significant DMRs identified in the $\mathrm{GBM}^{50}$ and $\mathrm{GBM}^{3}$ cohorts of tumours.

Both hyper- and hypo-methylated states were observed for tumours derived from cells with lower levels of mtDNA copy number. However, the majority of the DMRs were hypo-methylated compared to the GBM ${ }^{100}$ tumours (Table 1). There were 31 hyper-methylated DMRs (21.68\%) identified in the comparison between $\mathrm{GBM}^{0.2}$ and $\mathrm{GBM}^{100}$ tumours using an adjusted $p$ value of 0.05 . Indeed, the tendency to hypo-methylation was also observed in the other tumours. Taking the results identified using a $p$ value of, for instance, 0.001 , only $7.26 \%$ of the DMRs in the $\mathrm{GBM}^{50}$ tumours and $44.44 \%$ of the DMRs in the $\mathrm{GBM}^{3}$ tumours were hyper-methylated. The different proportions of hypo- and hyper-methylation further suggest that when tumorigenesis was initiated from different levels of mtDNA copy number, different patterns of DNA methylation were induced.

\section{The annotation of the DMRs and gene ontology analysis for the DMR-overlapping genes}

Firstly, the annotation of genomic regions was performed on the four groups of DMRs identified using the filters of a $p$ value $\leq 0.001$ and an adjusted $p$ value $\leq 0.05\left[\mathrm{GBM}^{50}\right.$ vs $\mathrm{GBM}^{100}(p \leq 0.001), \mathrm{GBM}^{3}$ vs $\mathrm{GBM}^{100}(p \leq 0.001)$, $\mathrm{GBM}^{0.2}$ vs $\mathrm{GBM}^{100}(p \leq 0.001)$ and $\mathrm{GBM}^{0.2}$ vs $\mathrm{GBM}^{100}$ (adjusted $p \leq 0.05$ )]. Overall, the results showed that over $49 \%$ of the DMRs were enriched in intragenic regions, namely exons, introns and promoter regions, and they were the most enriched regions (Fig. 2a-d). Each of these four groups of DMRs showed the greatest enrichment at introns, which was $52.51 \%$ of the $\mathrm{GBM}^{50}$ DMRs (Fig. 2a), 39.22\% of the GBM ${ }^{3}$ DMRs (Fig. 2b), 34.73\% of the $\mathrm{GBM}^{0.2}$ DMRs (Fig. 2c; $p \leq 0.001$ ) and $35.94 \%$ of the
GBM $^{0.2}$ DMRs (Fig. $2 \mathrm{~d}$; adjusted $p \leq 0.05$ ). For the $\mathrm{GBM}^{50}$ and $\mathrm{GBM}^{3}$ DMRs, the second most enriched regions were the distal intergenic regions, which were enriched at $22.35 \%$ and $37.25 \%$, respectively (Fig. $2 \mathrm{a}$, b). Interestingly, for the $\mathrm{GBM}^{0.2}$ DMRs, identified using the filters of $p \leq 0.001$ and adjusted $p \leq 0.05$, similar patterns were observed regardless of the numbers of DMRs (Fig. 2c, d). In contrast to the $\mathrm{GBM}^{50}$ and $\mathrm{GBM}^{3}$ DMRs, the second most enriched region for the $\mathrm{GBM}^{0.2}$ DMRs was the promoter regions, which were $23.60 \%$ and $25.81 \%$ of the DMRs after filtering at $p \leq 0.001$ and adjusted $p \leq 0.05$, respectively (Fig. 2c, d). The distal intergenic regions were ranked third accounting for $16.51 \%$ and $18.89 \%$ of the $\mathrm{GBM}^{0.2}$ DMRs identified using the filters of $p \leq 0.001$ and adjusted $p \leq 0.05$, respectively (Fig. 2c, d). Untranslated regions (UTRs), downstream regions of genes and super enhancers accounted for less than 14\% of the DMRs in each comparison. Interestingly, over $80 \%$ of the identified DMRs overlapped with topologically associating domains (TADs) that interact with other genomic regions and are considered to be the regulatory units of the genome [42].

To understand the related functions of the DMRs, functional classification and statistical overrepresentation analyses were performed on the DMR-overlapping genes using the PANTHER Classification System. The functional classification of the DMR-overlapping genes showed that the $\mathrm{GBM}^{50}$ and $\mathrm{GBM}^{3}$ tumours mostly clustered into cellular and metabolic processes (Fig. 3). Furthermore, the pathways of biological regulation, localization, response to stimuli and developmental processes were present in both cohorts (Fig. 3). Due to the large number of DMR-overlapping genes identified in the $\mathrm{GBM}^{0.2}$ tumours using the two different filters, statistical overrepresentation analysis was, therefore, performed. Interestingly, the biological processes enriched in the DMR-overlapping genes showed strong associations with developmental processes, especially in the DMRoverlapping genes identified with an adjusted $p$ value of 0.05 (Table 2). The common developmental pathways identified in both analyses (shown in italics) included developmental, nervous system development and cell differentiation processes (Table 2). This is in line with a previous finding that, after partial mtDNA depletion with 

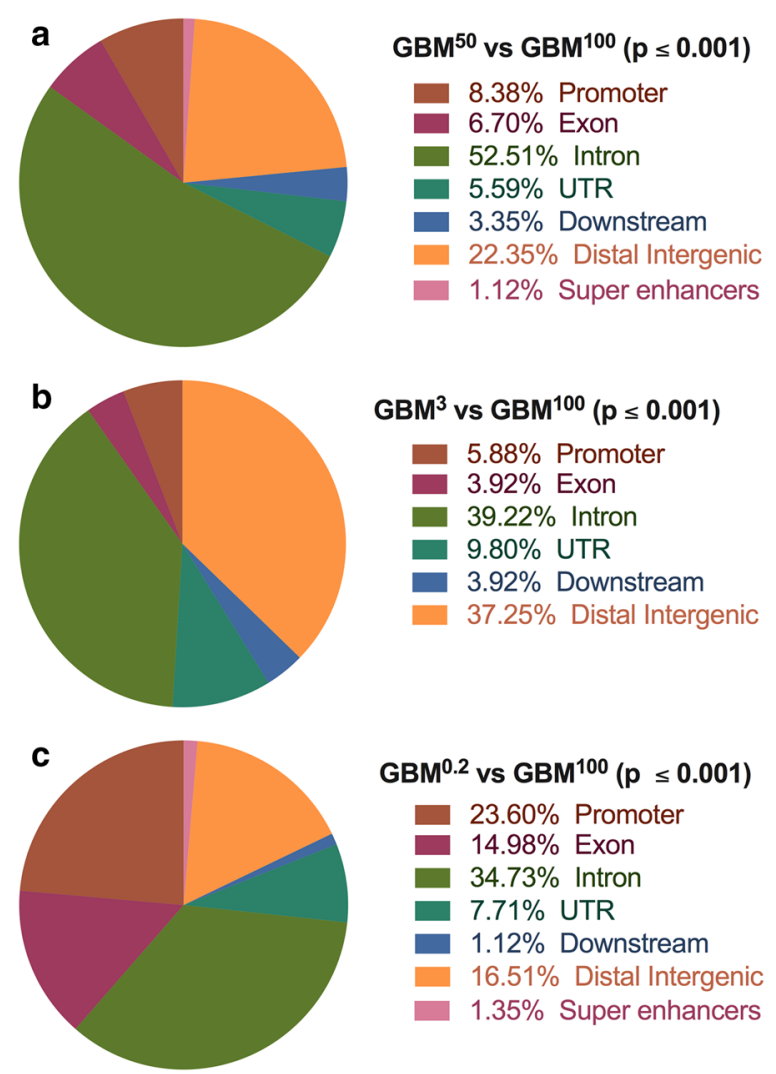

23.60\% Promoter

$14.98 \%$ Exon

$34.73 \%$ Intron

$7.71 \%$ UTR

$1.12 \%$ Downstream

$16.51 \%$ Distal Intergenic

$1.35 \%$ Super enhancers
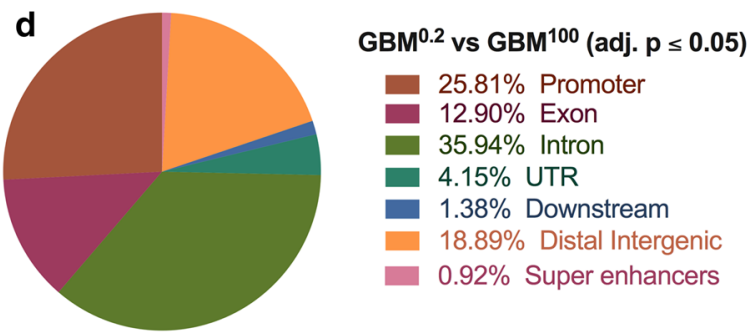

Fig. 2 Annotations of the DMRs. Based on their genomic locations, DMRs identified in the comparison: a $\mathrm{GBM}^{50}$ versus $\mathrm{GBM}^{100}$ $(p \leq 0.001)$; $\mathbf{b} \mathrm{GBM}^{3}$ versus $\mathrm{GBM}^{100}(p \leq 0.001)$; $\mathrm{c} \mathrm{GBM}^{0.2}$ versus $\mathrm{GBM}^{100}$ $(p \leq 0.001)$; and $\mathbf{d} \mathrm{GBM}^{0.2}$ versus $\mathrm{GBM}^{100}$ (adjusted. $p \leq 0.05$ ) were classified into promoters, exons, introns, UTRs, downstream regions, distal intergenic regions and super enhancers using the ChIPSeeker package ( $n=3$ tumours per group). DMR-overlapping regions in brown signify promoter regions, violet-red indicates exons, green indicates introns, blue indicates promoters, teal represents UTRs, blue represents downstream regions, orange indicates intergenic regions, and pink indicates super enhancers. The percentage of each group is indicated in the key to each figure

7 and 14-day ddC treatment, differentiation was able to take place in the GBM cells [18]. Moreover, regulation of transcription from the RNA polymerase II promoter was found to be commonly modulated, which reflected the potential for transcriptional changes that could result from the DMRs.
Validation of the gene expression of the regulators of DNA methylation

DNA methyltransferases (DNMTs), namely DNMT1/3A/3B, are responsible for catalysing DNA methylation at cytosines by converting them to 5-methylcytosines $(5 \mathrm{mC})$. On the other hand, the ten-eleven translocation (TET) enzymes, namely TET $1 / 2 / 3$, can demethylate $5 \mathrm{mC}$ to 5 -hydroxymethylcytosine $(5 \mathrm{hmC})$ $[27,28]$. The changes to these DNA methylation and demethylation factors can provide insights into how the changes to the DNA methylation profiles occurred. Therefore, the gene expression levels of the DNA methylation regulators were assessed using a custom-made Fluidigm qPCR array (Fig. 4). There was $\geq 1.5$-fold change in expression of DNMT1 in $\mathrm{GBM}^{50}$ and $\mathrm{GBM}^{0.2}$ tumours, suggesting that the reduction in mtDNA copy number strongly induced DNA demethylation in the tumours, and is probably the major reason why the majority of regions were hypo-methylated (Table 1 ). DNMT3A was also significantly down-regulated by over 1.5 -fold in the $\mathrm{GBM}^{50}$ tumours (Fig. 4). None of the DNA methylation factors was found to be differentially expressed in the $\mathrm{GBM}^{3}$ tumours compared with the $\mathrm{GBM}^{100}$ tumours, which further supported the results that fewer DMRs were identified in this group. The expression of TET1 showed a trend of up-regulation only in the $G_{B M}{ }^{0.2}$ tumours. As there was a higher percentage of hyperDMRs in the $\mathrm{GBM}^{0.2}$ tumours, the up-regulation of TET1 might be a response to counter the increased hypermethylation observed.

Furthermore, it has been reported that the genomes of low grade and secondary glioblastomas are extensively methylated to support the tumorigenic transcriptome that they exhibit [32, 38-40, 43]. This is further supported by the findings that the overexpression of the mutated isocitrate dehydrogenase (IDH1/2) in the citric acid cycle inhibits the activity of TET2 and thus contributes to the hyper-methylated genome [36-40]. However, the HSRGBM cell line possesses wild-type alleles for $I D H 1 / 2$ [34, 35 ], which makes it an excellent model to investigate the impact of mtDNA content in tumour-initiating cells on DNA methylation patterns during tumorigenesis, especially as non-mutated $I D H 1$ has been shown to promote cell growth in GBM [44]. We, therefore, investigated the expression of $I D H 1 / 2$ in these tumours and found that expression for both genes was down-regulated in the GBM $^{50}$ tumours (Fig. 4), which likely reduced their ability to induce hyper-methylation and supports the hypomethylation observed in these tumours. 


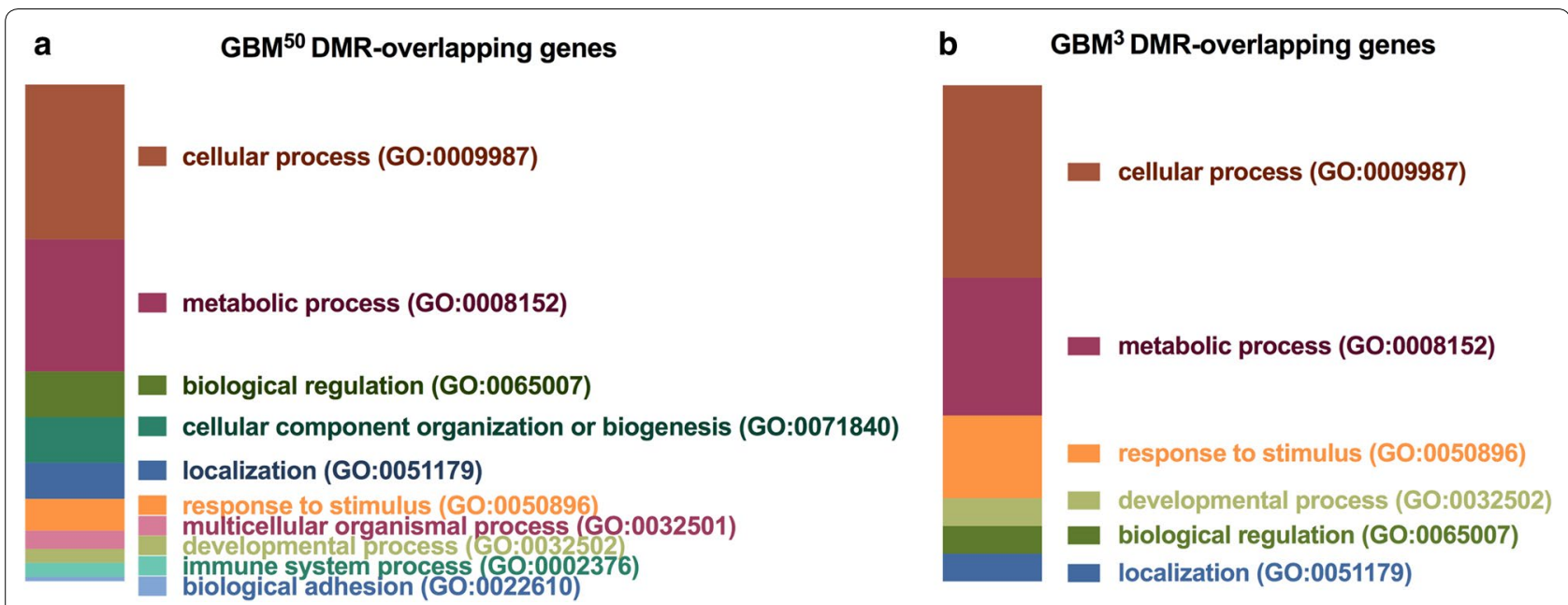

Fig. 3 Functional classification analysis of the DMR-overlapping genes in the $\mathrm{GBM}^{50}$ and $\mathrm{GBM}^{3}$ tumours. DMR-overlapping genes in: a GBM ${ }^{50}$ tumours; and $\mathbf{b} \mathrm{GBM}^{3}$ tumours were classified into subgroups based on their associated biological processes using the PANTHER system

\section{DMR-overlapping differentially expressed genes and differentiation markers after restoration of tumorigenic capacity}

To investigate which genes changed their patterns of expression in response to the altered levels of DNA methylation, we compared the identified DMRs with the differentially expressed genes previously reported on the same samples [17]. We focused on the DMRs identified using an adjusted $p$ value of 0.05 , which were considered to be the genomic regions that had undergone most significant changes in DNA methylation. There were 9 DMR-overlapping differentially expressed genes, namely BAIAP2, L3MBT1L, KCNC1, GPSM1, SLC27A1, MAF, OGFR, MICALL2 and RHOT2 (Fig. 5a). The changes to the levels of gene expression were further validated for these genes (Fig. 5a). Interestingly, the $\mathrm{GBM}^{3}$ tumours, with the least number of DMRs, showed more variable patterns in expression amongst the DMR-overlapping genes when compared with the $\mathrm{GBM}^{100}$ tumours. RHOT2 and $O G F R$ were significantly up-regulated in the $G^{3} M^{3}$ tumours $(p<0.05$ and $p<0.01$, respectively). The greater modification that occurred in the DNA methylation profiles of the $\mathrm{GBM}^{50}$ and $\mathrm{GBM}^{0.2}$ tumours promoted gene expression profiles more similar to the tumorigenic features of the $\mathrm{GBM}^{100}$ tumours, whereas less modification in the $\mathrm{GBM}^{3}$ tumours failed to mimic the transcriptional changes in these DMR-overlapping genes.

As the DMRs were found to be tightly associated with developmental processes (Fig. 3 and Table 2), we also focused on the neural markers and genes in neurogenesis that have been reported in cells having undergone
mtDNA depletion to the same levels as those used to form tumours [18]. Indeed, it has been previously shown that the partial mtDNA depletion of GBM cells could lead to increased expression of genes associated with early developmental processes [18]. In tumours formed from these cells, an overview of gene expression identified by RNA-Seq data is shown (Fig. 5b). Both up-regulation and down-regulation were observed. To make a comparison between the in vivo tumours and in vitro cells, the negative regulator of cell proliferation $A L K$ was found to be down-regulated in the mtDNA-depleted tumours. However, $A L K$ was found to be up-regulated in the mtDNA-depleted cultured cells. Likewise, the regulators of cell differentiation and proliferation, VEGFA, $D L G 4, C D K, N R P 2$ and $A C H E$, were also found to be down-regulated in the mtDNA-depleted tumours but presented higher levels of expression in the cells. The regulators of transcription and differentiation, ASCL1 and DLL1 in the Notch signalling pathway, were found to be up-regulated in the mtDNA-depleted tumours but down-regulated in the cells. The regulator of synaptogenesis, $A P O E$, was found to be up-regulated in the $\mathrm{GBM}^{50}$ and $\mathrm{GBM}^{3}$ tumours, but down-regulated in the $\mathrm{GBM}^{0.2}$ tumours and the mtDNA-depleted cells. Moreover, FGF13, SEMA4D, PAPD6B and NRCAM were found to be commonly up-regulated in both cells and tumours. As the cells recovered their tumorigenicity after restoration of mtDNA copy number in vivo, the shifts in gene expression between the tumours and the cells indicated that the restoration and maintenance of mtDNA copy number in 
Table 2 Pathways affected by the DMR-overlapping genes in the $\mathrm{GBM}^{0.2}$ tumours using the PANTHER Classification system

\begin{tabular}{|c|c|c|c|c|c|c|c|c|c|}
\hline $\begin{array}{l}\text { PANTHER } \\
\text { pathways }\end{array}$ & $\begin{array}{l}\text { Input/ } \\
\text { background }\end{array}$ & $\begin{array}{l}\text { Fold } \\
\text { enrichment }\end{array}$ & $p$ value & FDR & $\begin{array}{l}\text { PANTHER } \\
\text { pathways }\end{array}$ & $\begin{array}{l}\text { Input/ } \\
\text { background }\end{array}$ & $\begin{array}{l}\text { Fold } \\
\text { enrichment }\end{array}$ & $p$ value & FDR \\
\hline \multicolumn{5}{|c|}{ DMR-overlapping genes in the GBM ${ }^{0.2}$ tumours ( $p \leq 0.001$ ) } & \multicolumn{5}{|c|}{ DMR-overlapping genes in the GBM ${ }^{0.2}$ tumours (adj. $p \leq 0.05$ ) } \\
\hline $\begin{array}{l}\text { Cell differ- } \\
\text { entiation } \\
\text { (GO:0030154) }\end{array}$ & $191 / 548$ & 1.47 & $6.12 \mathrm{E}-06$ & $9.95 \mathrm{E}-05$ & $\begin{array}{l}\text { Cell differ- } \\
\text { entiation } \\
\text { (GO:0030154) }\end{array}$ & $9 / 459$ & 3.93 & $5.42 \mathrm{E}-04$ & 4.41E-02 \\
\hline $\begin{array}{l}\text { Nervous system } \\
\text { development } \\
\text { (GO:0007399) }\end{array}$ & $113 / 314$ & 1.52 & $1.88 \mathrm{E}-04$ & $1.76 \mathrm{E}-03$ & $\begin{array}{l}\text { Nervous system } \\
\text { Development } \\
\text { (GO:0007399) }\end{array}$ & $7 / 238$ & 5.89 & $2.23 \mathrm{E}-04$ & $5.45 \mathrm{E}-02$ \\
\hline \multirow[t]{3}{*}{$\begin{array}{l}\text { Regulation of } \\
\text { transcription } \\
\text { from RNA } \\
\text { polymerase } \\
\text { II promoter } \\
\text { (GO:0006357) }\end{array}$} & 196/598 & 1.39 & $9.47 \mathrm{E}-05$ & $9.63 \mathrm{E}-04$ & $\begin{array}{l}\text { Regulation of } \\
\text { transcription } \\
\text { from RNA } \\
\text { polymerase } \\
\text { II promoter } \\
\text { (GO:0006357) }\end{array}$ & $10 / 548$ & 3.66 & $4.61 \mathrm{E}-04$ & $5.63 \mathrm{E}-02$ \\
\hline & & & & & $\begin{array}{r}\text { Cellular process } \\
\text { (GO:0009987) }\end{array}$ & $57 / 7905$ & 1.45 & $5.54 \mathrm{E}-04$ & $2.70 E-02$ \\
\hline & & & & & $\begin{array}{l}\text { Behaviour } \\
\text { (GO:0007610) }\end{array}$ & $4 / 76$ & 10.55 & $6.79 \mathrm{E}-04$ & $2.76 \mathrm{E}-02$ \\
\hline $\begin{array}{l}\text { Developmen- } \\
\text { tal process } \\
\text { (GO:0032502) }\end{array}$ & $537 / 1501$ & 1.51 & $1.01 \mathrm{E}-16$ & $2.46 \mathrm{E}-14$ & & & & & \\
\hline $\begin{array}{l}\text { Sensory percep- } \\
\text { tion of smell } \\
\text { (GO:0007608) }\end{array}$ & $6 / 240$ & 0.11 & $1.41 \mathrm{E}-15$ & $1.72 \mathrm{E}-13$ & & & & & \\
\hline $\begin{array}{l}\text { Defence } \\
\text { response to } \\
\text { bacterium } \\
\text { (GO:0042742) }\end{array}$ & $0 / 112$ & $<0.01$ & $9.10 E-11$ & 4.44E-09 & & & & & \\
\hline $\begin{array}{l}\text { Response } \\
\text { to biotic } \\
\text { stimulus } \\
\text { (GO:0009607) }\end{array}$ & $3 / 144$ & 0.09 & $2.98 \mathrm{E}-10$ & $1.21 \mathrm{E}-08$ & & & & & \\
\hline $\begin{array}{l}\text { B cell mediated } \\
\text { immunity } \\
\text { (GO:0019724) }\end{array}$ & $0 / 94$ & $<0.01$ & $3.08 \mathrm{E}-09$ & $9.40 \mathrm{E}-08$ & & & & & \\
\hline $\begin{array}{l}\text { Complement } \\
\text { activation } \\
\text { (GO:0006956) }\end{array}$ & $1 / 94$ & 0.04 & $5.91 \mathrm{E}-08$ & $1.44 \mathrm{E}-06$ & & & & & \\
\hline $\begin{array}{l}\text { Ectoderm } \\
\text { development } \\
\text { (GO:0007398) }\end{array}$ & $96 / 212$ & 1.91 & $3.82 \mathrm{E}-07$ & $8.46 \mathrm{E}-06$ & & & & & \\
\hline $\begin{array}{l}\text { Cell recognition } \\
\text { (GO:0008037) }\end{array}$ & $4 / 105$ & 0.16 & $3.64 \mathrm{E}-06$ & $6.84 \mathrm{E}-05$ & & & & & \\
\hline $\begin{array}{l}\text { Mesoderm } \\
\text { development } \\
\text { (GO:0007498) }\end{array}$ & $109 / 269$ & 1.71 & $4.74 \mathrm{E}-06$ & $8.27 \mathrm{E}-05$ & & & & & \\
\hline $\begin{array}{l}\text { Phagocytosis } \\
\text { (GO:0006909) }\end{array}$ & $15 / 182$ & 0.35 & $9.91 \mathrm{E}-06$ & $1.42 \mathrm{E}-04$ & & & & & \\
\hline $\begin{array}{l}\text { Embryo } \\
\text { development } \\
\text { (GO:0009790) }\end{array}$ & $49 / 106$ & 1.95 & 1.96E-04 & 1.77E-03 & & & & & \\
\hline $\begin{array}{l}\text { Cellular com- } \\
\text { ponent mor- } \\
\text { phogenesis } \\
\text { (GO:0032989) }\end{array}$ & $144 / 423$ & 1.44 & $2.32 \mathrm{E}-04$ & $2.02 \mathrm{E}-03$ & & & & & \\
\hline $\begin{array}{l}\text { Biological } \\
\text { adhesion } \\
\text { (GO:0022610) }\end{array}$ & $124 / 356$ & 1.47 & $2.72 \mathrm{E}-04$ & $2.21 \mathrm{E}-03$ & & & & & \\
\hline
\end{tabular}


Table 2 (continued)

\begin{tabular}{|c|c|c|c|c|c|c|c|c|c|}
\hline $\begin{array}{l}\text { PANTHER } \\
\text { pathways }\end{array}$ & $\begin{array}{l}\text { Input/ } \\
\text { background }\end{array}$ & $\begin{array}{l}\text { Fold } \\
\text { enrichment }\end{array}$ & $p$ value & FDR & $\begin{array}{l}\text { PANTHER } \\
\text { pathways }\end{array}$ & $\begin{array}{l}\text { Input/ } \\
\text { background }\end{array}$ & $\begin{array}{l}\text { Fold } \\
\text { enrichment }\end{array}$ & $p$ value & FDR \\
\hline $\begin{array}{l}\text { Cell adhesion } \\
\text { (GO:0007155) }\end{array}$ & $124 / 356$ & 1.47 & $2.72 \mathrm{E}-04$ & $2.29 \mathrm{E}-03$ & & & & & \\
\hline $\begin{array}{l}\text { Segment } \\
\text { specification } \\
\text { (GO:0007379) }\end{array}$ & $37 / 78$ & 2.01 & 7.86E-04 & $5.99 \mathrm{E}-03$ & & & & & \\
\hline $\begin{array}{l}\text { Transmembrane } \\
\text { receptor pro- } \\
\text { tein tyrosine } \\
\text { kinase signal- } \\
\text { ling pathway } \\
\text { (GO:0007169) }\end{array}$ & $60 / 151$ & 1.68 & $1.07 \mathrm{E}-03$ & $7.90 \mathrm{E}-03$ & & & & & \\
\hline $\begin{array}{l}\text { Negative } \\
\text { regulation } \\
\text { of apoptotic } \\
\text { process } \\
\text { (GO:0043066) }\end{array}$ & $43 / 99$ & 1.84 & $1.25 E-03$ & $8.73 E-03$ & & & & & \\
\hline $\begin{array}{l}\text { Regulation of } \\
\text { phosphate } \\
\text { metabolic } \\
\text { process } \\
\text { (GO:0019220) }\end{array}$ & $169 / 537$ & 1.33 & $1.34 \mathrm{E}-03$ & $8.86 \mathrm{E}-03$ & & & & & \\
\hline $\begin{array}{l}\text { Intracel- } \\
\text { lular signal } \\
\text { transduction } \\
\text { (GO:0035556) }\end{array}$ & $310 / 1071$ & 1.22 & $1.55 E-03$ & $9.92 \mathrm{E}-03$ & & & & & \\
\hline $\begin{array}{l}\text { Anterior/pos- } \\
\text { terior axis } \\
\text { specification } \\
\text { (GO:0009948) }\end{array}$ & $12 / 16$ & 3.17 & 3.37E-03 & $1.96 \mathrm{E}-02$ & & & & & \\
\hline $\begin{array}{l}\text { Cytoskeleton } \\
\text { organization } \\
\text { (GO:0007010) }\end{array}$ & $129 / 404$ & 1.35 & $3.74 \mathrm{E}-03$ & $2.12 \mathrm{E}-02$ & & & & & \\
\hline $\begin{array}{l}\text { Synaptic } \\
\text { transmission } \\
\text { (GO:0007268) }\end{array}$ & $121 / 382$ & 1.34 & $5.92 \mathrm{E}-03$ & $3.28 \mathrm{E}-02$ & & & & & \\
\hline
\end{tabular}

Common processes are highlighted in italics

tumorigenesis is tightly associated with the regulation of differentiation.

\section{Modulation of the mtDNA replication factors for the maintenance of mtDNA copy number in tumorigenesis}

As mtDNA copy number was replenished to similar levels in each of the tumour types (Fig. 1), we determined how the mtDNA-specific replication factors were affected. In total, 20 known mtDNA replication factors were screened for differentially methylated intragenic CpG islands (CGIs). The fold changes in relative methylation scores for the $\mathrm{GBM}^{100}$ tumours of 28 promoter and gene-body CGIs within the mtDNA replication factors were plotted (Fig. 6a). An increasing trend in fold changes was observed from the $\mathrm{GBM}^{50}$ to the $\mathrm{GBM}^{0.2}$ tumours. Particularly, for the CGIs, higher levels of methylation were found in the $\mathrm{GBM}^{50}$ tumours compared to the $\mathrm{GBM}^{100}$ tumours (shown in red blocks) and the fold changes generally increased to an even higher level in the $\mathrm{GBM}^{0.2}$ tumours. This trend was mostly observed amongst the gene-body CGIs. For the CGIs that were more hypo-methylated in the $\mathrm{GBM}^{50}$ tumours than the $\mathrm{GBM}^{100}$ tumours (shown in blue blocks), the levels of DNA demethylation were indicative of minor shifts in the GBM $^{0.2}$ tumours.

Furthermore, the gene expression levels were also assessed using a Fluidigm qPCR array (Fig. 6b). Overall, the levels of expression of the mtDNA replication factors in the tumours formed from cells possessing varying levels of mtDNA were found to be down-regulated, which likely restricts $\mathrm{mtDNA}$ replication during tumorigenesis after the restoration of mtDNA copy number to its original levels. ESRRA, NRF1, POLG, PPARGCA1 and SIRT1 were identified to be significantly down-regulated in all of the mtDNA-depleted tumours. The mtDNA replication 


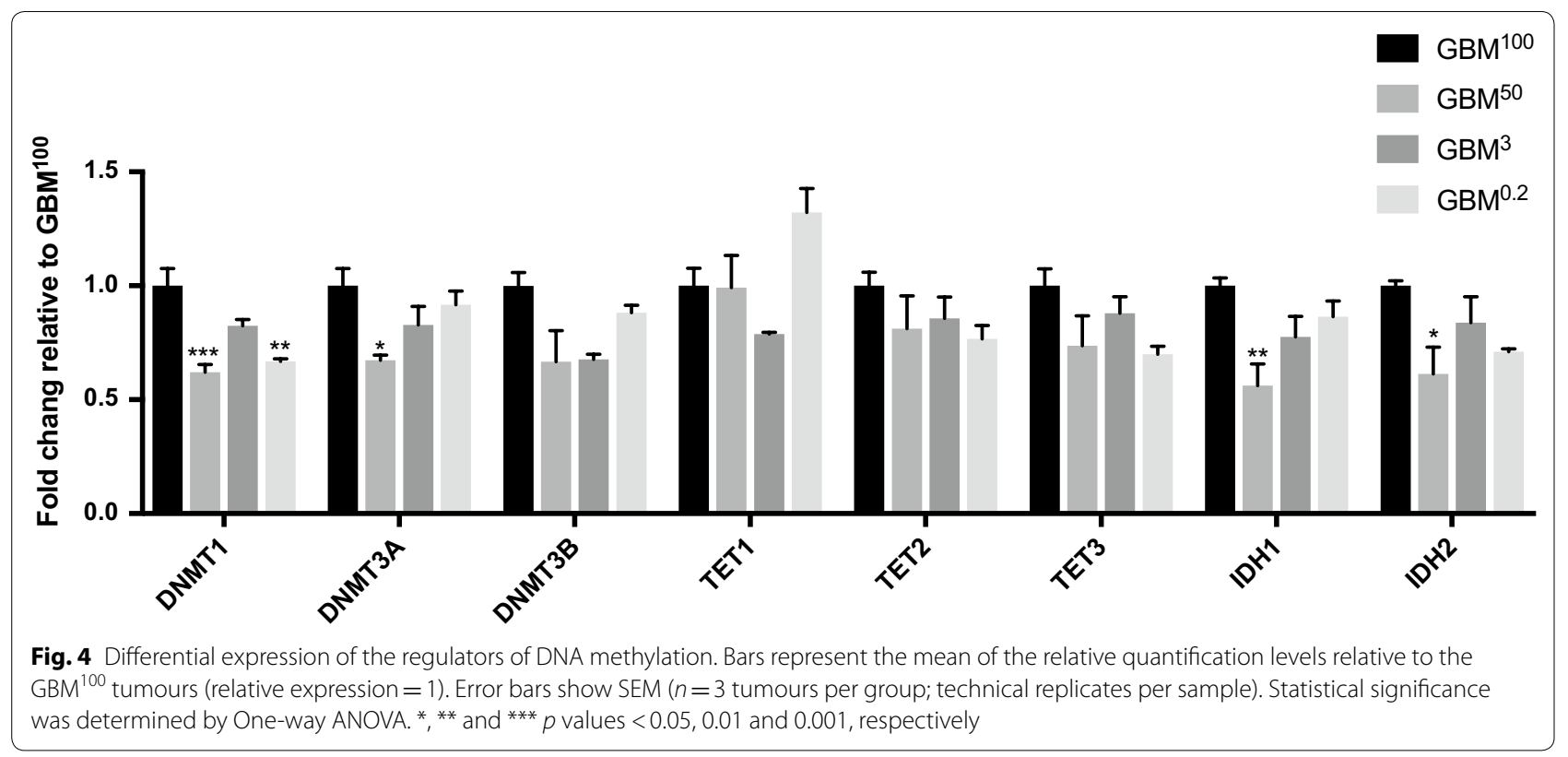

factors POLG2, TOP1 MT and TWNK were also found to be down-regulated in the $\mathrm{GBM}^{50}$ and $\mathrm{GBM}^{3}$ tumours. Moreover, the key mtDNA transcription factors $P O L$ RMT, TFAM, TFB1M and TFB2M were down-regulated in the $\mathrm{GBM}^{50}$ and $\mathrm{GBM}^{3}$ tumours. NRF2 and SIRT3 were only down-regulated in the $\mathrm{GBM}^{50}$ tumours. The hypoxia regulator STAT3 was found to be significantly down-regulated in the $\mathrm{GBM}^{50}$ and $\mathrm{GBM}^{0.2}$ tumours. ESRRG was only down-regulated in the $\mathrm{GBM}^{3}$ tumours. This indicates that mtDNA replenishment had been completed and the low levels of expression of the mtDNA replication factors were indicative of mtDNA turnover during cell division rather than the active repopulation of depleted cells with mtDNA.

\section{Discussion}

We have shown that bidirectional cooperation between the nuclear and mitochondrial genomes is important for tumour formation. To this extent, the DNA methylation and gene expression profiles of the nuclear genome were extensively modulated following the restoration of mtDNA copy number to pre-depletion levels in tumours that developed to end point. Whilst it is conceivable that the mtDNA depletion process did not reduce mtDNA copy in individual cells from each group uniformly, it is unlikely that this occurred. If a small population of cells with higher mtDNA copy number had been selected for, there would have been greater similarity amongst the DNA methylation and gene expression profiles across the groups. However, cells from each group exhibited distinct gene expression profiles prior to inoculation [18] and DNA methylation and gene expression profiles as end point tumours.

The restoration of mtDNA copy number can be achieved through the cell's own mtDNA replication machinery or the horizontal transfer of mitochondria from surrounding cells [17, 45, 46]. It was previously shown that the same tumours possessed only human mtDNA and not mouse mtDNA from the surrounding stroma [47]. However, the restoration of mtDNA copy number also involved the accumulation of mtDNA variants, which increased in number as a function of the degree of restoration of mtDNA copy number. Each of the tumours exhibited a gain in de novo variants primarily associated with ND4 and ND6, which encode subunits of complex I of the electron transfer chain, and the D-loop. However, these variants have been identified in other GBM cell lines [47]. Consequently, the presence and modulation of mtDNA are important to tumorigenesis given that cells require mtDNA to be fully functional [48].

The effects of DNA methylation on transcription vary dependent on the location of the methylated sites. Methylated CGIs within the promoter regions are known to repress transcription [49], whereas methylation within gene bodies correlates positively and negatively with transcriptional elongation [50]. In our work, the degree of restoration of mtDNA copy number differentially affected the levels of DNA methylation in the end point tumours. However, the majority of the DMRs were hypo-methylated in each comparison. Whilst there was 


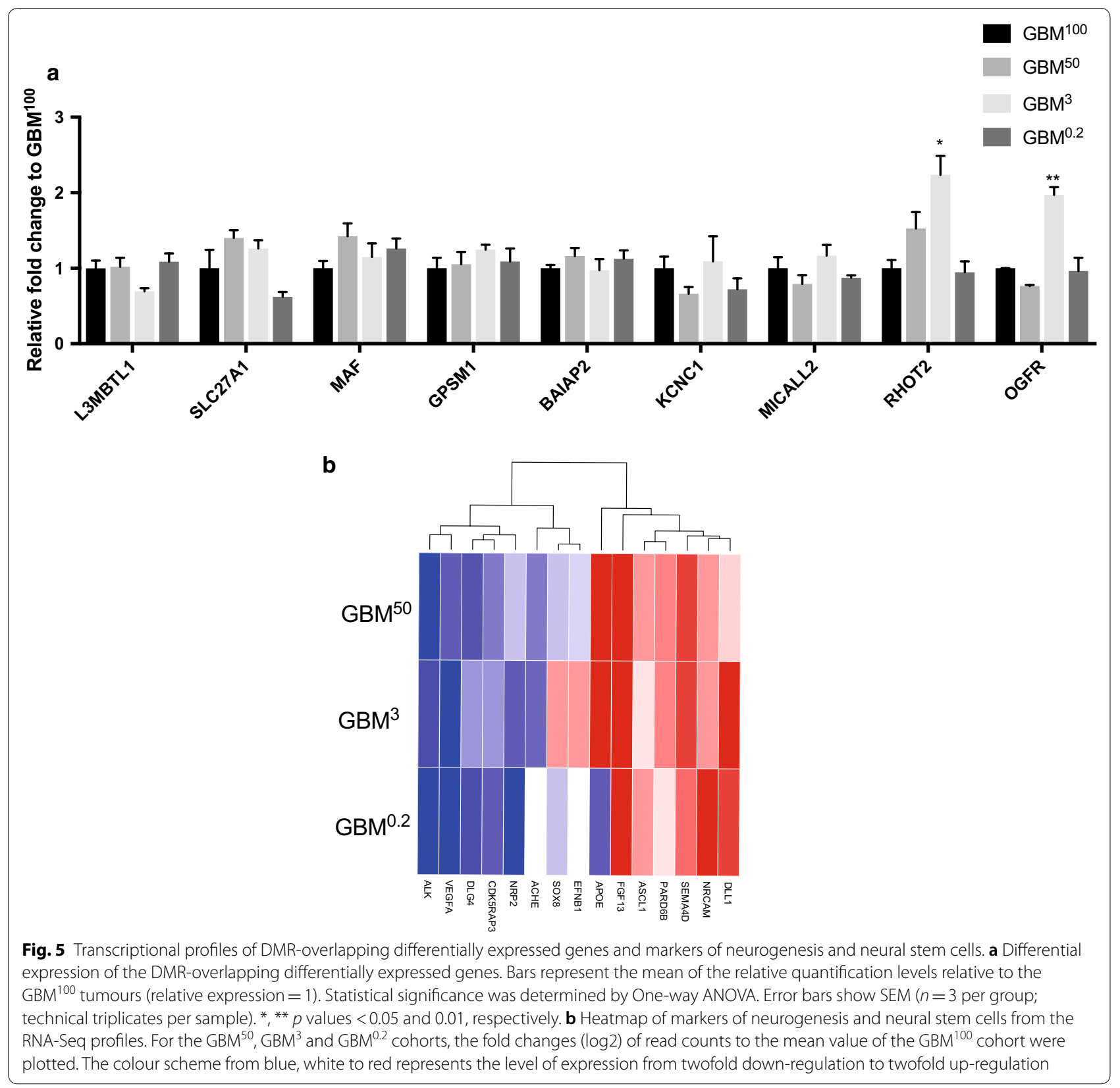

high enrichment in the intragenic regions, namely promoters, exons and introns, there were differences in the numbers of DMRs affected and their distribution across the nuclear genome, especially for the promoter and exon regions amongst the comparisons. The DMRs in the $\mathrm{GBM}^{50}$ and $\mathrm{GBM}^{0.2}$ tumours also overlapped with several enhancers, which are documented to contribute to tumour progression and cancer cell plasticity [51]. Furthermore, over $80 \%$ of the DMRs overlapped with TADs, the regulatory units of the genome [42], which suggests that their modulation could affect the structural formation and, therefore, genetic activities of the genome [42].

These outcomes are likely mediated by the down-regulation in levels of expression of the DNA methyltransferases, especially DNMT1. For the GBM ${ }^{0.2}$ tumours, DNA demethylation was further enhanced by the upregulation of $T E T 1$, which mediates the transition from $5 \mathrm{mC}$ to $5 \mathrm{hmC}$ [52], resulting in these tumours being most hypo-methylated. IDH1 and IDH2, the cytoplasmic and mitochondrial isoforms respectively, had lower levels of expression in the tumours derived from 


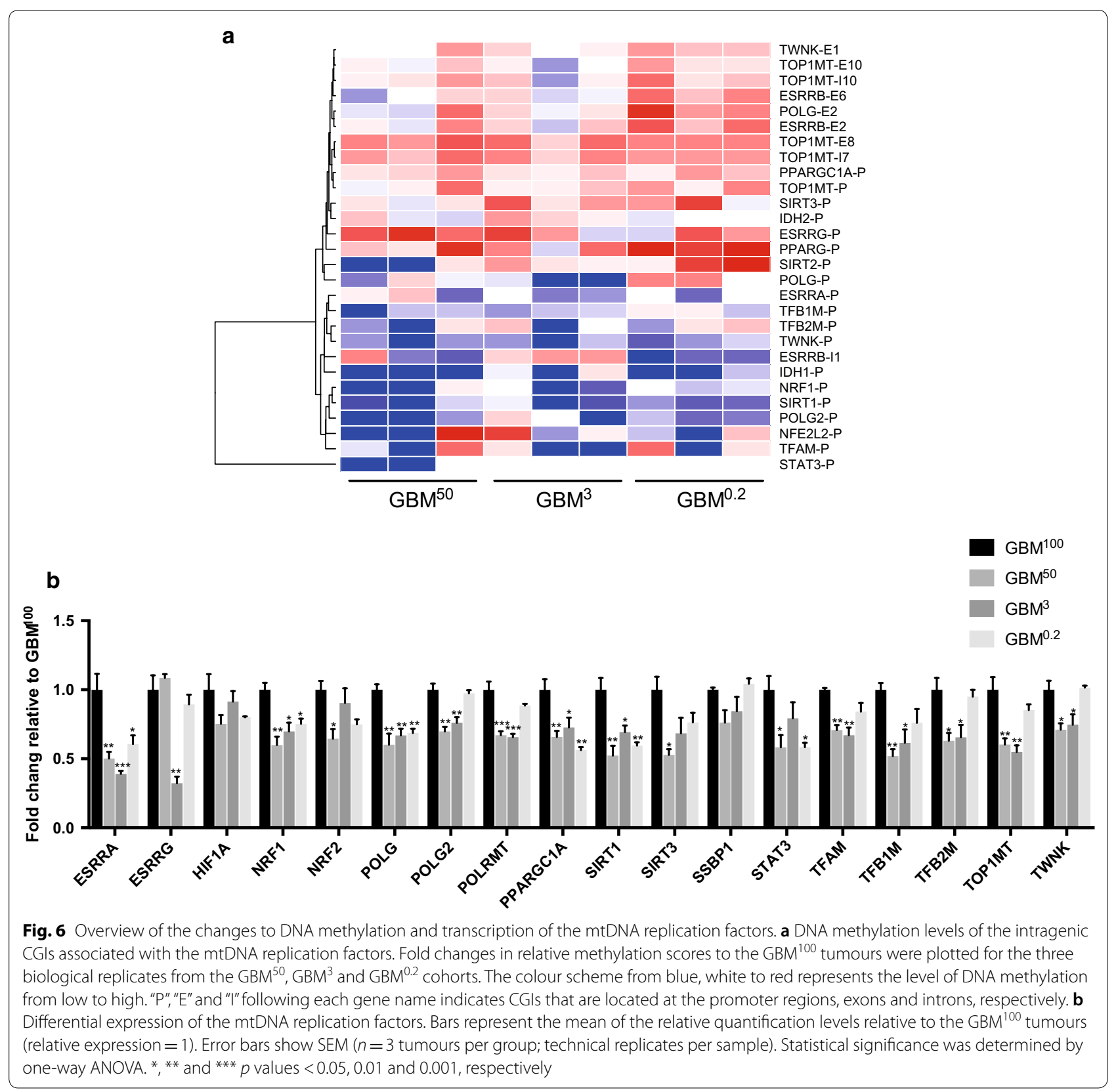

mtDNA-depleted cells than GBM $^{100}$ tumours. This suggests that $\alpha$-ketoglutarate could continue to act as a cofactor of the TET enzymes and did not induce a switch to 2-hydroxyglutarate to promote hyper-methylation $[43,44,53]$. This is consistent with HSR-GBM1 cells possessing wild type copies of the IDH genes [34, 35], which is common in high-grade (IV) astrocytomas [38, $40,44]$. One-carbon metabolism also takes place in the mitochondria resulting in the generation of $\mathrm{S}$-adenosylmethionine, the universal methyl group donor [54]. $\mathrm{S}$-adenosylmethionine is present at abnormal levels in cancer cells and could affect DNA methylation profiles during tumorigenesis [54]. We would anticipate that $\mathrm{S}$-adenosylmethionine activity was down-regulated as a result of mtDNA depletion, which reduces mitochondrial function [55], and, thus, promotes the hypo-methylated state of the resultant tumours.

During early development, large-scale DNA demethylation takes place to reset the nuclear genome to a naïve state $[27,28]$. This is coupled with the strict regulation of mtDNA copy number to establish the mtDNA set point [15]. As a result, the two genomes 
act in tandem to overcome a number of molecular check points at different stages of development, which include mtDNA replication turnover events [56]. Indeed, Polg-/- mice do not possess sufficient mtDNA at E6.5 and cannot initiate mtDNA replication at this key developmental check point and, consequently, die [57]. Likewise, somatic cells reprogrammed to a naïve, pluripotent state, similar to embryonic stem cells, can fail to re-establish the mtDNA set point and lose their differentiation potential [56]. HSR-GBM1 cells are cancer stem cells that express key early neural markers, maintain low mtDNA copy number and use glycolysis for energy production, which are typical facets of a stem cell [33]. However, when they are induced to differentiate into high OXPHOS-derived ATP requiring cells, for example neurons and astrocytes, they fail to replicate mtDNA in synchrony with changes to the nuclear genome and their progress stalls [56]. Nevertheless, mtDNA partially depleted HSR-GBM1 cells can re-establish their mtDNA set point and expand their mtDNA copy number in order to complete differentiation [18] (please refer to Fig. 7 'in vitro'). However, the degree of restoration of mtDNA copy number influenced the differentiation and transcriptional potentials of the cells as determined by RNA-Seq analysis of end point tumours. The most affected networks between the $\mathrm{GBM}^{100}$ and the $\mathrm{GBM}^{0.2}$ and $\mathrm{GBM}^{3}$ tumours were cellular development, cellular growth and proliferation, whilst cancer, cell cycle and cellular development were most affected in the $\mathrm{GBM}^{50}$ tumours [17].

Although the $\mathrm{GBM}^{50}$ tumours are more aggressive, they appear to restrict mtDNA replenishment to predepletion levels, which ensures that the balance between mtDNA copy number and the methylation of the chromosomal genome is at levels that promote tumorigenesis, as is the case for the $\mathrm{GBM}^{3}$ and $\mathrm{GBM}^{0.2}$ tumours. From a mtDNA perspective, there is increased hyper-methylation in the majority of gene-body CGIs of the mtDNA replication factors of the mtDNA-depleted tumours compared with the $\mathrm{GBM}^{100}$ tumours. This is exemplified by increased methylation at exon 2 of POLG and exon 8 of TOP1MT and decreased levels of expression for these two genes, which are known to regulate mtDNA copy number in a cell-specific manner through DNA methylation at these intragenic regions [15, 16, 31]. Interestingly, the use of DNA methylation agents, such as 5-Azacytidine and Vitamin C, on cultured HSR-GBM1 and reprogrammed somatic cells can restore mtDNA replication turnover events and promote differentiation [16], which likely explains the use of these agents in clinical settings for cancer patients $[58,59]$.

The DMR-overlapping genes affected a variety of biological processes. In the $\mathrm{GBM}^{50}$ and $\mathrm{GBM}^{3}$ tumours, the primary effects were on cellular and metabolic processes.

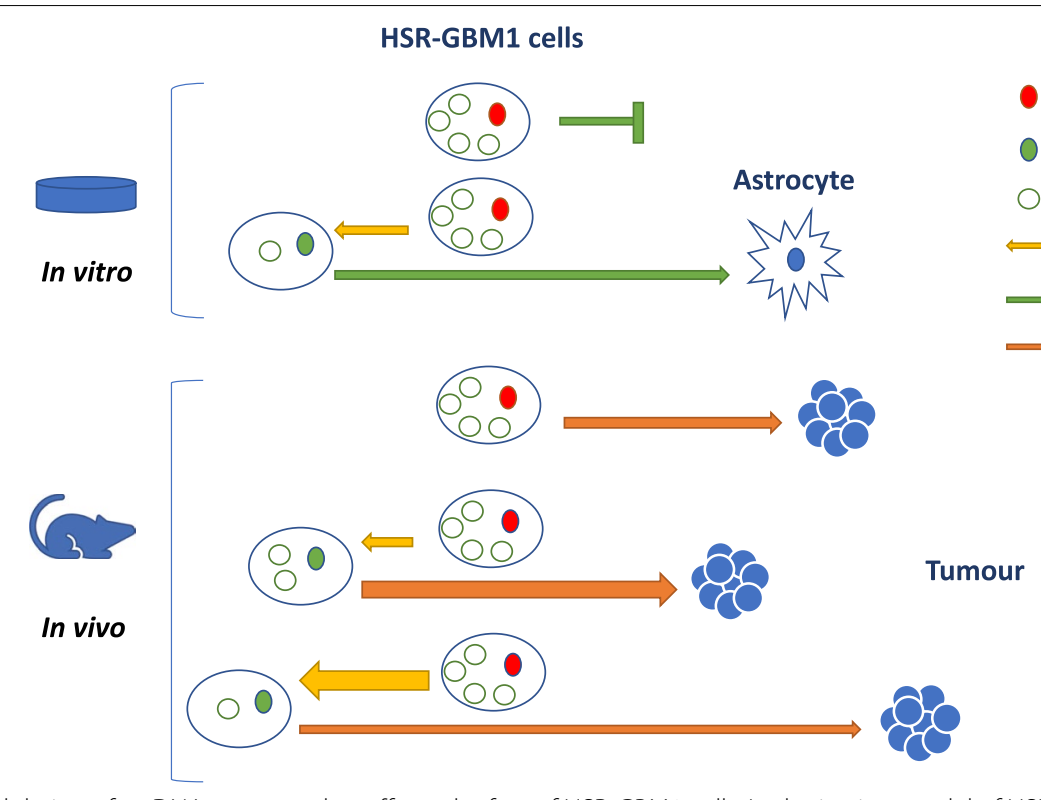

Fig. 7 Modulation of mtDNA copy number affects the fate of HSR-GBM1 cells. In the in vitro model of HSR-GBM1 cells, depletion of mtDNA (yellow arrow) for $7 / 14$ days results in demethylation of the nuclear genome (green) and rescues differentiation to astrocytes that is otherwise blocked (green arrow). In the in vivo model of HSR-GBM1 cells, varying levels of depletion result in different frequencies of progression to tumorigenesis (orange arrow). 50\% depletion accelerated tumorigenesis (thicker orange arrow), whereas further depletion slowed the initiation of tumorigenesis by modulating differentiation networks, nuclear gene expression and the mtDNA replication factors 
In the $\mathrm{GBM}^{0.2}$ tumours, developmental processes were more overrepresented, including cell differentiation and nervous system development. Of the nine DMR-overlapping differentially expressed genes, four were specific to neurogenesis. SLC27A1 was significantly down-regulated in a $S O X 2$-knockdown GBM cell line characterized by abolished dedifferentiation and decreased tumorigenesis [60]. Mutations in $K C N C 1$ have been reported as the driving cause for progressive myoclonus epilepsies [61]. Indeed, a number of DNA methylation signatures have been identified in several neurodevelopmental syndromes, including Coffin-Siris, Kabuki and CHARGE syndromes, which are implicated in a variety of cancers $[62,63]$.

Although the $\mathrm{GBM}^{3}$ tumours presented with the least number of DMRs, they had more variable patterns of expression amongst the DMR-overlapping genes. For example, RHOT2 and OGFR were significantly up-regulated in the $\mathrm{GBM}^{3}$ tumours. RHOT2 is a miro GTPase that regulates mitochondrial transport, distribution and dynamics, especially in neurodegenerative disorders $[64,65]$, and is differentially expressed in different types $\left(\mathrm{CD}_{133^{+}}\right.$and $\left.\mathrm{CD} 133^{-}\right)$of GBM stem cells [66]. It is usually only expressed in type I GBM cancer stem cells and is co-expressed with the stem cell markers SOX2, SOX11 and OLIG2 [66]. This indicates the expression of RHOT2 is important for regulating mitochondria and their dynamics during early development, which requires the presence of mtDNA given that cells need mtDNA to be fully functional [48]. On the other hand, OGFR is a negative regulator of cell proliferation and reduces proliferation of astrocytes in cell culture [67]. Consequently, $\mathrm{GBM}^{3}$ tumours differentially expressed two genes associated with different stages of development unlike the other tumour types. Nevertheless, the greater levels of modification that occurred in the DNA methylation profiles of the $\mathrm{GBM}^{50}$ and $\mathrm{GBM}^{0.2}$ tumours promoted gene expression profiles more indicative of the tumorigenic features of the $\mathrm{GBM}^{100}$ tumours. A similar situation has been observed in tumour cell lines possessing the same chromosomal background but different mtDNA haplotypes where early tumours from each haplotype expressed a distinct set of genes [68]. However, in this case, a series of commonly expressed genes were expressed again highlighting how the mitochondrial genome can affect tumorigenesis.

It is evident that $\mathrm{GBM}^{0.2}$ cells, which had undergone a longer period of mtDNA depletion through an agent that specifically targets POLG from interacting with the mitochondrial genome [69], adopted a more dedifferentiated state than the partially depleted cell types, as demonstrated by the expression of early neural developmental genes [18]. Indeed, many key regulators of cell proliferation and differentiation were down-regulated in the mtDNA-depleted tumours, but up-regulated in the mtDNA-depleted cells [18], whilst regulators of transcription and differentiation in the Notch signalling pathway were up-regulated in the tumours derived from mtDNA-depleted cells but down-regulated in the cells [18]. Likewise, the regulator of synaptogenesis, $A P O E$, was up-regulated in the $\mathrm{GBM}^{50}$ and $\mathrm{GBM}^{3}$ tumours but down-regulated in the mtDNA-depleted cells [18]. Consequently, since the mtDNA-depleted cells recovered their tumorigenicity as mtDNA copy number was restored in vivo, it is evident that the restoration and maintenance of mtDNA copy number in tumour-initiating cells is tightly associated with the regulation of neural differentiation in glioblastoma.

The regulation of mtDNA copy number, DNA methylation and nuclear gene expression at different stages of development highlights the need for cells to establish a balance between these three components to promote their specific fates. In the case of tumours derived from cells with different levels of mtDNA, unique DNA methylation profiles are established that regulate gene expression and mtDNA copy number in end point tumours (see Fig. 7 'in vivo'). To this extent, GBM ${ }^{0.2}$ cells attempted to modulate global DNA methylation patterns and transcription of the mtDNA replication factors and differentiation markers at the expense of tumorigenesis resulting in fewer tumours forming and requiring significantly longer to form. However, $\mathrm{GBM}^{50}$ cells were more tumorigenic, as they had struck the appropriate balance between mtDNA copy number and the methylated state of the chromosomal genome to promote tumorigenesis. The proposed model shown in Fig. 7 indicates how modulation of mtDNA copy number in tumour-initiating cells induces changes to DNA methylation of the nuclear genome and, therefore, can affect the fate of tumour cells in in vitro and in vivo environments. This highlights the synergy required between the two genomes in establishing tumorigenesis.

\section{Conclusions}

In all, we have shown that the restoration of mtDNA copy number during tumorigenesis induces major changes to the nuclear genome that resulted in differential DNA methylation and expression of genes. These changes enriched developmental processes and essential metabolic pathways associated with GBM. In addition, the changes to the nuclear-encoded mtDNA replication factors highlight the synergy between the nuclear and mitochondrial genomes in restoring tumorigenic capacity. This was clearly demonstrated in the $\mathrm{GBM}^{0.2}$ tumours formed from cells having undergone the highest levels of depletion and requiring the longest to initiate tumour 
formation. They underwent more extensive DNA methylation remodelling at key CGIs and within the intragenic regions of the mtDNA replication factors to maintain similar transcriptional levels. Whilst we recognize that we have only focused on the HSR-GBM1 tumour model, our results highlight the bidirectional control of the nuclear and mitochondrial genomes through modulation of DNA methylation in response to mtDNA copy number and to control gene expression in tumorigenesis.

\section{Methods}

\section{Cell culture and Xenograft models}

GBM tumours were previously generated from HSRGBM1 cells possessing different levels of mtDNA copy number after treatment with $10 \mu \mathrm{m} 2^{\prime}-3^{\prime}$-dideoxycytidine (ddC), a mtDNA depletion agent that directly inhibits the interaction of POLG with the mitochondrial genome [69], in the presence of $50 \mathrm{mg} / \mathrm{mL}$ uridine (Sigma-Aldrich, MO, USA). Cells were depleted to 50\% $\left(\mathrm{GBM}^{50}\right), 3 \%\left(\mathrm{GBM}^{3}\right), 0.2 \%\left(\mathrm{GBM}^{0.2}\right)$, and $100 \%\left(\mathrm{GBM}^{100}\right)$ of their original mtDNA content, as described in [18]. To this extent, HSR-GBM1 cells were cultured in complete neural stem cell media consisting of Dulbecco's Modified Eagle Medium/Nutrient Mixture (DMEM/F-12) Media (Thermo Fisher Scientific, MA, USA), 2\% StemPro neural supplement (Thermo Fisher Scientific), $20 \mathrm{ng} / \mathrm{mL}$ basic fibroblast growth factor (bFGF; Merck Millipore MO, USA) and $20 \mathrm{ng} / \mathrm{mL}$ epidermal growth factor (EGF; Merck Millipore) at $37{ }^{\circ} \mathrm{C}, 5 \% \mathrm{CO}_{2}$ and $95 \%$ humidity.

The animal work was approved by the Animal Ethics Committee, Monash University, Approval Number: MMCA/2011/76. Briefly, 0.5 million HSR-GBM1 tumour cells in $100 \mathrm{~mL}$ of medium were inoculated subcutaneously into both flanks of 5- to 6-week-old, female BALB/c nude mice (Animal Research Centre, Perth, Australia). Tumour growth rates and volumes were reported in [18]. For each group, cells were injected into 12 mice to form tumours, as detailed in [18]. In all, 11 tumours formed from $\mathrm{GBM}^{100}$ cells, 10 from $\mathrm{GBM}^{50}$ cells, 6 from $\mathrm{GBM}^{3}$ cells and 2 from $\mathrm{GBM}^{0.2}$ cells [18]. GBM ${ }^{100}$ tumours reached an average volume of $175 \mathrm{~mm}^{3}$ at 65 days, $\mathrm{GBM}^{50}$ tumours reached an average volume of $250 \mathrm{~mm}^{3}$ at 61 days $(p>0.05), \mathrm{GBM}^{3}$ tumours reached an average volume of $\sim 150 \mathrm{~mm}^{3}$ at 83 days $(p<0.01)$, and $\mathrm{GBM}^{0.2}$ tumours reached an average volume of $>200 \mathrm{~mm}^{3}$ at 90 days $(p<0.01)[18]$.

\section{DNA extraction}

Total genomic DNA was extracted from the tumours using the DNeasy Blood \& Tissue Kits (Qiagen, CA, USA), according to manufacturer's protocols with minor modifications. The DNA samples were treated with $3 \mu \mathrm{L}$ of RNase solution (Qiagen) at room temperature. DNA samples were eluted in $100 \mu \mathrm{L}$ of autoclaved Milli-Q $\mathrm{H}_{2} \mathrm{O}$.

\section{Determination of $\mathrm{mtDNA}$ copy number per cell}

mtDNA copy number per cell was determined, as previously described [16]. To this extent, concentrations of $\mathrm{qPCR}$ products for $\beta$-globin and mtDNA were determined against standard curves generated by quantitative real-time PCR (qPCR; Rotor-Gene 3000, Corbett Research, Cambridge, UK) on total DNA purified from the tumours ( $n=3$ per group; $n=3$ replicates per sample). Primer sequences and primer-specific reaction conditions are listed in Additional file 3. mtDNA copy number per cell was calculated using the formula of $2 \times N_{\text {mtDNA }} / N_{\beta \text {-globin, }}$ where, for $N_{\text {mtDNA }}$ and $N_{\beta \text {-globin }}$, $N=\left(\right.$ qPCR product concentration $\left.\times 6.023 \times 10^{14}\right) /(\mathrm{qPCR}$ product size in $\mathrm{bp} \times 660$ ).

\section{Immunoprecipitation of methylated DNA sequencing (MeDIP-Seq)}

Five microgram of genomic DNA from each of the tumour samples ( $n=3$ per group) underwent MeDIP, as previously described [70]. Briefly, each DNA sample was sheared into 200-1000 bp using the Covaris Adaptive Focused Acoustics $\left(\mathrm{AFA}^{\mathrm{TM}}\right.$ ) S220 system (Woburn, MA, USA). dsDNA was then denatured to single-stranded DNA, as required for the antibody, by incubation at $95^{\circ} \mathrm{C}$ for $10 \mathrm{~min} .3 \mu \mathrm{g}$ of each DNA sample was immunoprecipitated with $2 \mu \mathrm{g}$ of anti- $5 \mathrm{mC}$ antibody (Active Motif) with $20 \mu \mathrm{L}$ per sample of prewashed Dynabeads ${ }^{\circledR}$ Protein G (Thermo Fisher Scientific). The suspension was incubated in $500 \mu \mathrm{L}$ of IP buffer (100 mM sodium phosphate (pH 7.0); $1.4 \mathrm{M} \mathrm{NaCl} ; 0.5 \%$ Triton $\mathrm{X}-100)$ at $4{ }^{\circ} \mathrm{C}$ for $16 \mathrm{~h}$ under rotation. The beads were then washed three times with $1 \mathrm{~mL}$ of IP buffer and resuspended in $250 \mu \mathrm{L}$ of proteinase $\mathrm{K}$ digestion buffer $(50 \mathrm{mM}$ Tris- $\mathrm{HCl}, \mathrm{pH}$ 8.0; $10 \mathrm{M}$ EDTA, pH 8.0; 1.0\% SDS) with $10 \mu \mathrm{L}$ of proteinase $\mathrm{K}(20 \mathrm{mg} / \mathrm{mL}$; Bioline, London, UK). The suspension was incubated at $50{ }^{\circ} \mathrm{C}$ for $3 \mathrm{~h}$ on a thermo-shaker. The supernatant was then collected on a magnetic particle concentrator (Thermo Fisher Scientific). DNA was purified from the supernatant using the QIAquick PCR Purification Kit (Qiagen), according to the manufacturer's protocol.

MeDIP products from each of the tumour samples underwent library construction using the DNA SMART ChIP-Seq Kit (Clontech, CA, USA), as per the manufacturer's protocol (No. 021115). Libraries were quality checked using Qubit fluorometric quantitation (Thermo Fisher Scientific), a 2100 Bioanalyzer (Agilent, CA, USA), and qPCR. All libraries were of a similar size (297$335 \mathrm{bp})$ and quantities $(\sim 40 \mathrm{ng} / \mu \mathrm{l})$. A single equimolar 
pool was made following denaturation of the libraries at $94{ }^{\circ} \mathrm{C}$ for $2 \mathrm{~min} .12 \mathrm{pM}$ of each library was used for onboard cluster generation and sequencing in 4 lanes of two consecutive Illumina HiSeq 1500 Rapid runs. Cluster densities were within the optimal range of 881$959 \mathrm{k} / \mathrm{mm}^{2}$ (optimal $750-1000 \mathrm{k} / \mathrm{mm}^{2}$ ). This resulted in around 170 million readable clusters per lane. $95 \%$ of the clusters passed filter, and $96 \%$ of the reads passed the Illumina sequencing quality score of Q30, which was deemed excellent quality for base-calling. Run quality parameters with the PhiX spike-in had an error rate of $0.12 \%$ (expected $<0.5 \%$ ) and phasing/pre-phasing of $<0.13 /<0.10$ (expected $<0.4 /<0.2$ ).

\section{Computational analysis for MeDIP-Seq Mapping}

Computational analysis was performed on the MeDIPSeq sequences using the customized analytical pipeline, as described in [31]. Briefly, the sequences were firstly checked for quality and adaptors using the FastQC software ( $\mathrm{v}$ 0.11.5). The raw sequences were then aligned to the human reference genome GRCh38/hg38 (UCSC) using the Burrows-Wheeler Aligner (BWA) software (version 0.7.16a) in the single-end mode of the BWAbacktrack algorithm with default settings [71]. The output files (".sam) were then combined and converted to bam files (".bam) by SAMtools (version 1.4).

\section{Determination of differentially methylated regions (DMRs)} Uniquely mapped reads with mapping scores (MAPQ) $\geq 30$ were kept for analytical analysis using the MEDIPS package (version 1.24.0), according to the command codes of the MEDIPS package. Briefly, the reads were cleaned for PCR duplicates that mapped to exactly the same genomic positions by setting the parameter "uniq" to 1 . The reads were then extended to 500 nucleotides according to the reference genome without any shift in the genomic locations by setting the parameter "extend" to 500 and "shift" to 0 . The coverage of every 100 -bp window of the genome was summarized by setting the parameter "window_size" to 100. MeDIP-Seqspecific quality control analysis was performed on each sample, which includes saturation analysis and $\mathrm{CpG}$ enrichment analysis. A coupling factor was set up based on the $\mathrm{GBM}^{100}$ sample for normalization. Differentially methylated windows (DMWs) with the total count of reads $\geq 100$ (minrowsum $=100$ ) were identified between groups using the 'edgeR' method. Statistically significant DMWs were selected for downstream analysis. Continuous significant DMWs were merged as one DMR (Additional file 4).

\section{Annotation of DMRs}

DMRs then underwent annotation based on their corresponding genomic regions in the human genome using the ChIPSeeker package (version 3.5) [72]. Superenhancer annotation was performed using the dbSUPER databases [73]. TAD overlapping analysis was conducted using the TAD datasets available in The ENCODE project [74]. Gene lists were analysed for gene ontology using the Panther Classification System (version 12.0) [75]. The functional classification analysis was used to annotate the functions of genes. The statistical overrepresentation test (Fisher's exact test with a false discovery rate (FDR) correction) was used to identify the significance of associated biological processes overrepresented amongst the genes.

\section{Region-of-Interest (ROI) analysis}

DNA methylation levels at particular regions of the genome, for example CGIs associated with the mtDNA replication factors, were assessed by the built-in ROI analysis in the MEDIPS package. DNA methylation levels of ROIs were expressed as relative methylation scores, as determined by the MEDIPS package. The relative methylation score was developed specifically for MeDIP-Seq in order to normalize methylation scores for regions based on the concept of CpG coupling analysis [76, 77].

\section{Determination of copy number variation (CNV)}

Total DNA from the tumour samples ( $n=3$ per group) was submitted to the Australian Genome Research Facility (AGRF; VIC, AUS) to perform genotyping. The Illumina Human Global Screening Array Beadchip (Illumina) was used, which covers approximately $700 \mathrm{~K}$ SNPs throughout the genome. Array data were normalized, clustered and underwent genotype calling using the Genotype Module of GenomeStudio 2.0 (Illumina), according to the user's manual. The full data report containing log $\mathrm{R}$ ratios and $\mathrm{B}$ allele frequencies for each probe was then exported and analysed using Nexus 9.0 software (BioDiscovery Inc., CA, USA). The Nexus Copy Number Module was used to identify regions of $\mathrm{CN}$ gain and loss, loss of heterozygosity ( $\mathrm{LOH}$ ) for each group and statistically significant CNVs between groups ( $p$ value $\leq 0.05$ ). Human genome hy19 was chosen as the reference genome to annotate the genomic locations. Genomic regions were then aligned to human genome hg38, allowing overlapping analysis with the DMRs using the 'intersect' function of bedtools (v2.24.0) [78, 79].

\section{Identification of DMR-overlapping differentially expressed genes}

RNA-Seq was previously performed on the GBM tumours [17]. The sequencing files were deposited in the 
NCBI Sequence Read Archive (SRA) under the accession code PRJNA296542 [17]. The sequences were mapped to the human genome (hg19) using the Tophat aligner (v1.3.1) [17, 80]. Differentially expressed genes were determined using the Cufflinks tool (v2.2.1) [17, 80]. Differentially expressed genes $(F D R \leq 0.05)$ underwent liftover analysis to match the hg38 human genome assembly using the GALAXY platform (usegalaxy.org) and then overlapping analysis was performed with the DMRs using the 'intersect' function of bedtools (v2.24.0) [78, 79].

\section{Gene expression analysis using real-time quantitative PCR}

Total genomic RNA was extracted from the tumour samples ( $n=3$ per group) using the RNeasy Mini Kit and the QIAshredder (Qiagen, CA, USA), according to manufacturer's protocols with minor modifications. The RNA samples were treated with DNase I (Qiagen) on column for 20 min. cDNA was synthesized from $1 \mu \mathrm{g}$ of the total RNA using the Superscript III First-Strand synthesis system (Thermo Fisher Scientific), according to the manufacturer's instructions.

cDNA products ( $n=3$ technical replicates per tumour) were assessed using the Rotor-Gene 3000 RT-PCR machine under primer-specific conditions (Additional file 3), as described in [16]. Relative gene expression to the $\mathrm{GBM}^{100}$ tumours was calculated using the $\triangle \Delta \mathrm{CT}$ method. OAZ1, 18SrRNA and HPRT1 were used as the housekeeping genes, of which the mean values of expression were used as the internal control for data normalization [31]. Data were represented as the fold change to the $\mathrm{GBM}^{100}$ group $(n=3$; mean \pm SEM). One-way ANOVA was used to determine statistical significance between the $\mathrm{GBM}^{50}, \mathrm{GBM}^{3}$ and $\mathrm{GBM}^{0.2}$ tumours and the $\mathrm{GBM}^{100}$ tumours. Results were plotted using GraphPad Prism 7 (GraphPad Software, Inc., CA, USA).

\section{Gene expression analysis using the Fluidigm platform}

Using the same sets of cDNA samples $(n=3$ per group; $n=2$ replicates per sample), gene expression of targets of interest was assessed using the Fluidigm qPCR array, according to the manufacturer's instructions. Taqman primers are listed in Additional file 5. Taqman primers were pooled and diluted in C1 DNA suspension buffer to a final concentration for each primer of $180 \mathrm{nM}$. Each cDNA sample and a non-template control underwent pre-amplification for 14 cycles, according to the manufacturer's instructions (Quick Reference PN 100$5876 \mathrm{~B} 1)$. The pre-amplification reaction consisted of the Taqman PreAmp Master mix (Thermo Fisher Scientific) and the pooled Taqman primers. Products were diluted fivefold with C1 DNA suspension buffer. The integrated fluidic circuit controller HX was then used to prime and load the 96.96 Dynamic array plate. $5 \mu \mathrm{L}$ of each sample was loaded in duplicate into each sample inlet and $5 \mu \mathrm{L}$ of each Taqman assay $(10 \mathrm{x})$ were loaded into each assay inlet. Real-time qPCR was performed according to the Biomark GE 96.96 Standard v2 protocol. Data were exported using the Fluidigm real-time PCR analysis software (v4.1.1). Relative gene expression was calculated using the same method described above.

\section{Additional files}

Additional file 1. MeDIP-Seq specific QC results determined by the MEDIPS package.

Additional file 2. Summary of CNV regions identified in each cohort of tumours and overlapping with DMRs using the Nexus 9.0 software.

Additional file 3. Primer pairs for real time PCR.

Additional file 4. DMRs identified using MeDIP-Seq and MEDIPS package. Additional file 5. Taqman assays used in the Fluidigm qPCR arrays.

\section{Abbreviations}

mtDNA: mitochondrial DNA; OXPHOS: oxidative phosphorylation; POLG: polymerase gamma subunit A; POLG2: polymerase gamma subunit B; TWNK: mitochondrial helicase; SSBP1: single-stranded DNA binding protein; TOP1MT: mitochondrial topoisomerase; TFAM: mitochondrial transcription factors A; TFB1M: mitochondrial transcription factors B1; TFB2M: mitochondrial transcription factors B2; NRF1/2: nuclear respiratory factors 1/2; PPARG: peroxisome proliferator-activated receptor $\gamma$; PPARGC1A: peroxisome proliferator-activated receptor $\gamma$ co-activator; SIRT1-3: Sirtuin family of genes 1-3; ESRRA/B/G: oestrogen-related receptors A/B/G; TET: ten-eleven translocation methylcytosine dioxygenases; DNMT: DNA methyltransferase family; GBM: glioblastoma multiforme; MeDIP: methylated DNA immunoprecipitation; $\mathrm{GBM}^{100}$ : tumours formed from cells possessing $100 \%$ of their mtDNA content; $\mathrm{GBM}^{50}$ : tumours formed from cells possessing $50 \%$ of their mtDNA content; GBM ${ }^{3}$ : tumours formed from cells possessing 3\% of mtDNA content; GBM ${ }^{0.2}$ : tumours formed from cells possessing $0.2 \%$ of mtDNA content; DMW: differentially methylated windows; DMR: differentially methylated regions; ROI: region of interest; CNV: copy number variation; $5 \mathrm{mC}$ : 5-methylcytosine; $\mathrm{hmC}$ : 5-hydroxymethylcytosine; CGI: CpG island; TADs: topologically associating domains; UTR: untranslated regions; ddC: 2'-3'-dideoxycytidine; BWA: Burrows-Wheeler Aligner; FDR: false discovery rate; $\mathrm{LOH}$ : loss of heterozygosity.

\section{Authors' contributions}

XS designed and performed the experiments, analysed the data and drafted the manuscript. JCSJ conceived the work, designed and coordinated the experiments, analysed the data, drafted the manuscript and obtained funding for the work. Both authors read and approved the final manuscript.

\section{Author details}

${ }_{1}^{1}$ Mitochondrial Genetics Group, Hudson Institute of Medical Research, 27-31 Wright Street, Clayton, VIC 3168, Australia. ${ }^{2}$ Department of Molecular and Translational Sciences, Monash University, 27-31 Wright Street, Clayton, VIC 3168, Australia.

\section{Acknowledgements}

We are grateful to Dr. Trevor Wilson and Dr. Selva Kumari Ramasubramanian, The Medical Genomics Facility, Monash Health Translation Precinct, for assistance in performing MeDIP-Seq and the Fluidigm real-time qPCR array, respectively. We are also grateful to BioDiscovery, Inc for the use of Nexus

Copy Number software in our data analysis.

\section{Competing interests}

The authors declare that they have no competing interests. 


\section{Availability of data and materials}

The MeDIP-Seq datasets supporting the conclusions of this article are available in Sequence Read Archive (SRA) and are accessible through accession number PRJNA397951. The CNV datasets supporting the conclusions of this article are available in the Gene Expression Omnibus (GEO) and are available under accession number GSE98366. The RNA-Seq datasets supporting the conclusions of this article are available in SRA and are obtainable under accession number PRJNA296542, as detailed in [17].

\section{Consent for publication}

Not applicable.

\section{Ethics approval and consent to participate}

The animal work was approved by the Animal Ethics Committee, Monash University, Approval Number: MMCA/2011/76.

\section{Funding}

This work was supported by Hudson Institute of Medical Research Discretionary Funds, and the Victorian Government's Operational Infrastructure Support Program. XS was supported by an Australian Postgraduate Award.

\section{Publisher's Note}

Springer Nature remains neutral with regard to jurisdictional claims in published maps and institutional affiliations.

Received: 11 June 2018 Accepted: 6 September 2018 Published online: 12 September 2018

\section{References}

1. Anderson S, Bankier AT, Barrell BG, de Bruijn MH, Coulson AR, Drouin J, Eperon IC, Nierlich DP, Roe BA, Sanger F, et al. Sequence and organization of the human mitochondrial genome. Nature. 1981;290:457-65.

2. Kasamatsu H, Grossman LI, Robberson DL, Watson R, Vinograd J. The replication and structure of mitochondrial DNA in animal cells. Cold Spring Harb Symp Quant Biol. 1974;38:281-8.

3. Clayton DA. Replication of animal mitochondrial DNA. Cell. 1982;28:693-705.

4. Carrodeguas JA, Theis K, Bogenhagen DF, Kisker C. Crystal structure and deletion analysis show that the accessory subunit of mammalian DNA polymerase gamma, Pol gamma B, functions as a homodimer. Mol Cell. 2001;7:43-54

5. Takamatsu C, Umeda S, Ohsato T, Ohno T, Abe Y, Fukuoh A, Shinagawa H, Hamasaki N, Kang D. Regulation of mitochondrial D-loops by transcription factor $\mathrm{A}$ and single-stranded DNA-binding protein. EMBO Rep. 2002;3:451-6.

6. Korhonen JA, Gaspari M, Falkenberg M. TWINKLE Has 5' $\rightarrow 3^{\prime}$ DNA helicase activity and is specifically stimulated by mitochondrial singlestranded DNA-binding protein. J Biol Chem. 2003;278:48627-32.

7. Zhang H, Meng LH, Pommier Y. Mitochondrial topoisomerases and alternative splicing of the human TOP1mt gene. Biochimie. 2007;89:474-81.

8. Fisher RP, Clayton DA. Purification and characterization of human mitochondrial transcription factor 1. Mol Cell Biol. 1988;8:3496-509.

9. Falkenberg M, Gaspari M, Rantanen A, Trifunovic A, Larsson NG, Gustafsson CM. Mitochondrial transcription factors B1 and B2 activate transcription of human mtDNA. Nat Genet. 2002;31:289-94.

10. Gleyzer N, Vercauteren K, Scarpulla RC. Control of mitochondrial transcription specificity factors (TFB1M and TFB2M) by nuclear respiratory factors (NRF-1 and NRF-2) and PGC-1 family coactivators. Mol Cell Biol. 2005;25:1354-66.

11. Aquilano K, Vigilanza P, Baldelli S, Pagliei B, Rotilio G, Ciriolo MR. Peroxisome proliferator-activated receptor gamma co-activator 1alpha (PGC-1alpha) and sirtuin 1 (SIRT1) reside in mitochondria: possible direct function in mitochondrial biogenesis. J Biol Chem. 2010;285:21590-9.

12. Chen JQ, Delannoy M, Cooke C, Yager JD. Mitochondrial localization of ERalpha and ERbeta in human MCF7 cells. Am J Physiol Endocrinol Metab. 2004:286:E1011-22.

13. Schreiber SN, Emter R, Hock MB, Knutti D, Cardenas J, Podvinec M, Oakeley EJ, Kralli A. The estrogen-related receptor alpha (ERRalpha) functions in PPARgamma coactivator 1alpha (PGC-1alpha)-induced mitochondrial biogenesis. Proc Natl Acad Sci USA. 2004;101:6472-7.

14. Kong X, Wang R, Xue Y, Liu X, Zhang H, Chen Y, Fang F, Chang Y. Sirtuin 3, a new target of PGC-1alpha, plays an important role in the suppression of ROS and mitochondrial biogenesis. PLoS ONE. 2010;5:e11707.

15. Kelly RD, Mahmud A, McKenzie M, Trounce IA, St John JC. Mitochondrial DNA copy number is regulated in a tissue specific manner by DNA methylation of the nuclear-encoded DNA polymerase gamma A. Nucleic Acids Res. 2012;40:10124-38.

16. Lee W, Johnson J, Gough DJ, Donoghue J, Cagnone GL, Vaghjiani V, Brown KA, Johns TG, St John JC. Mitochondrial DNA copy number is regulated by DNA methylation and demethylation of POLGA in stem and cancer cells and their differentiated progeny. Cell Death Dis. 2015;6:e1664.

17. Lee WT, Cain JE, Cuddihy A, Johnson J, Dickinson A, Yeung KY, Kumar B, Johns TG, Watkins DN, Spencer A, St John JC. Mitochondrial DNA plasticity is an essential inducer of tumorigenesis. Cell Death Discov. 2016;2:16016

18. Dickinson A, Yeung KY, Donoghue J, Baker MJ, Kelly RD, McKenzie M, Johns TG, St John JC. The regulation of mitochondrial DNA copy number in glioblastoma cells. Cell Death Differ. 2013;20:1644-53.

19. Sun X, St John JC. The role of the mtDNA set point in differentiation, development and tumorigenesis. Biochem J. 2016;473:2955-71.

20. Facucho-Oliveira JM, Alderson J, Splikings EC, Egginton S, St. John JC. Mitochondria DNA replication during differentiation of murine embryonic stem cells. J Cell Sci. 2007;15:4025-34.

21. Facucho-Oliveira JM, St John JC. The relationship between pluripotency and mitochondrial DNA proliferation during early embryo development and embryonic stem cell differentiation. Stem Cell Rev. 2009;5:140-58.

22. El Shourbagy SH, Spikings EC, Freitas M, St John JC. Mitochondria directly influence fertilisation outcome in the pig. Reproduction. 2006;131:233-45.

23. Spikings EC, Alderson J, St John JC. Regulated mitochondrial DNA replication during oocyte maturation is essential for successful porcine embryonic development. Biol Reprod. 2007;76:327-35.

24. Reynier P, May-Panloup P, Chretien MF, Morgan CJ, Jean M, Savagner F, Barriere P, Malthiery Y. Mitochondrial DNA content affects the fertilizability of human oocytes. Mol Hum Reprod. 2001;7:425-9.

25. Santos TA, El Shourbagy S, St John JC. Mitochondrial content reflects oocyte variability and fertilization outcome. Fertil Steril. 2006;85:584-91.

26. Lee WT, St John J. The control of mitochondrial DNA replication during development and tumorigenesis. Ann NY Acad Sci. 2015;1350:95-106.

27. Guo F, Li X, Liang D, Li T, Zhu P, Guo H, Wu X, Wen L, Gu TP, Hu B, et al. Active and passive demethylation of male and female pronuclear DNA in the mammalian zygote. Cell Stem Cell. 2014;15:447-59.

28. Brunner AL, Johnson DS, Kim SW, Valouev A, Reddy TE, Neff NF, Anton E, Medina C, Nguyen L, Chiao E, et al. Distinct DNA methylation patterns characterize differentiated human embryonic stem cells and developing human fetal liver. Genome Res. 2009;19:1044-56.

29. Jones PA, Taylor SM. Cellular differentiation, cytidine analogs and DNA methylation. Cell. 1980;20:85-93.

30. Blaschke K, Ebata KT, Karimi MM, Zepeda-Martinez JA, Goyal P, Mahapatra S, Tam A, Laird DJ, Hirst M, Rao A, et al. Vitamin[thinsp]C induces Tetdependent DNA demethylation and a blastocyst-like state in ES cells. Nature. 2013;500:222-6.

31. Sun X, Johnson J, St John JC. Global DNA methylation synergistically regulates the nuclear and mitochondrial genomes in glioblastoma cells. Nucleic Acids Res. 2018:46:5977-95.

32. Marie SK, Shinjo SM. Metabolism and brain cancer. Clinics (Sao Paulo). 2011;66(Suppl 1):33-43.

33. Galli R, Binda E, Orfanelli U, Cipelletti B, Gritti A, De Vitis S, Fiocco R, Foroni C, Dimeco F, Vescovi A. Isolation and characterization of tumorigenic, stem-like neural precursors from human glioblastoma. Cancer Res. 2004;64:7011-21.

34. Chu Q, Orr BA, Semenkow S, Bar EE, Eberhart CG. Prolonged inhibition of glioblastoma xenograft initiation and clonogenic growth following in vivo Notch blockade. Clin Cancer Res. 2013:19:3224-33.

35. Spina R, Voss DM, Asnaghi L, Sloan A, Bar EE. Atracurium Besylate and other neuromuscular blocking agents promote astroglial differentiation and deplete glioblastoma stem cells. Oncotarget. 2016;7:459-72.

36. Hess KR, Broglio KR, Bondy ML. Adult glioma incidence trends in the United States, 1977-2000. Cancer. 2004;101:2293-9. 
37. Figueroa ME, Abdel-Wahab O, Lu C, Ward PS, Patel J, Shih A, Li Y, Bhagwat $\mathrm{N}$, Vasanthakumar A, Fernandez HF, et al. Leukemic IDH1 and IDH2 mutations result in a hypermethylation phenotype, disrupt TET2 function, and impair hematopoietic differentiation. Cancer Cell. 2010;18:553-67.

38. Turcan S, Rohle D, Goenka A, Walsh LA, Fang F, Yilmaz E, Campos C, Fabius AW, Lu C, Ward PS, et al. IDH1 mutation is sufficient to establish the glioma hypermethylator phenotype. Nature. 2012;483:479-83.

39. Yan H, Parsons DW, Jin G, McLendon R, Rasheed BA, Yuan W, Kos I, BatinicHaberle I, Jones S, Riggins GJ, et al. IDH1 and IDH2 mutations in gliomas. N Engl J Med. 2009;360:765-73.

40. Cohen AL, Holmen SL, Colman H. IDH1 and IDH2 mutations in gliomas. Curr Neurol Neurosci Rep. 2013;13:345.

41. Robinson MD, Stirzaker C, Statham AL, Coolen MW, Song JZ, Nair SS, Strbenac D, Speed TP, Clark SJ. Evaluation of affinity-based genome-wide DNA methylation data: effects of CpG density, amplification bias, and copy number variation. Genome Res. 2010;20:1719-29.

42. Nothjunge S, Nuhrenberg TG, Gruning BA, Doppler SA, Preiss I S, Schwaderer M, Rommel C, Krane M, Hein L, Gilsbach R. DNA methylation signatures follow preformed chromatin compartments in cardiac myocytes. Nat Commun. 2017:8:1667.

43. Haseeb A, Makki MS, Haqqi TM. Modulation of ten-eleven translocation 1 (TET1), Isocitrate Dehydrogenase (IDH) expression, alpha-Ketoglutarate (alpha-KG), and DNA hydroxymethylation levels by interleukin-1 beta in primary human chondrocytes. J Biol Chem. 2014;289:6877-85.

44. Calvert AE, Chalastanis A, Wu Y, Hurley LA, Kouri FM, Bi Y, Kachman M, May $J$, Bartom E, Hua Y, et al. Cancer-associated IDH1 promotes growth and resistance to targeted therapies in the absence of mutation. Cell Rep. 2017;19:1858-73.

45. Tan AS, Baty JW, Dong LF, Bezawork-Geleta A, Endaya B, Goodwin J, Bajzikova M, Kovarova J, Peterka M, Yan B, et al. Mitochondrial genome acquisition restores respiratory function and tumorigenic potential of cancer cells without mitochondrial DNA. Cell Metab. 2015;21:81-94.

46. Dong LF, Kovarova J, Bajzikova M, Bezawork-Geleta A, Svec D, Endaya B, Sachaphibulkij K, Coelho AR, Sebkova N, Ruzickova A, et al. Horizontal transfer of whole mitochondria restores tumorigenic potential in mitochondrial DNA-deficient cancer cells. Elife. 2017:6:e22187.

47. Yeung KY, Dickinson A, Donoghue JF, Polekhina G, White SJ, Grammatopoulos DK, McKenzie M, Johns TG, St John JC. The identification of mitochondrial DNA variants in glioblastoma multiforme. Acta Neuropathol Commun. 2014;2:1.

48. Heller S, Schubert S, Krehan M, Schafer I, Seibel M, Latorre D, Villani G, Seibel P. Efficient repopulation of genetically derived rho zero cells with exogenous mitochondria. PLoS ONE. 2013;8:e73207.

49. Deaton AM, Bird A. CpG islands and the regulation of transcription. Genes Dev. 2011;25:1010-22

50. Yang X, Han H, De Carvalho DD, Lay FD, Jones PA, Liang G. Gene body methylation can alter gene expression and is a therapeutic target in cancer. Cancer Cell. 2014;26:577-90.

51. Bell RE, Golan T, Sheinboim D, Malcov H, Amar D, Salamon A, Liron T, Gelfman S, Gabet Y, Shamir R, Levy C. Enhancer methylation dynamics contribute to cancer plasticity and patient mortality. Genome Res. 2016;26:601-11.

52. Shen $L$, Zhang Y. Enzymatic analysis of Tet proteins: key enzymes in the metabolism of DNA methylation. Methods Enzymol. 2012;512:93-105.

53. Scourzic L, Mouly E, Bernard OA. TET proteins and the control of cytosine demethylation in cancer. Genome Med. 2015;7:9.

54. Cuyas E, Fernandez-Arroyo S, Verdura S, Garcia RA, Stursa J, Werner L, Blanco-Gonzalez E, Montes-Bayon M, Joven J, Viollet B, et al. Metformin regulates global DNA methylation via mitochondrial one-carbon metabolism. Oncogene. 2018;37:963-70.

55. Chen H, Wang J, Liu Z, Yang H, Zhu Y, Zhao M, Liu Y, Yan M. Mitochondrial DNA depletion causes decreased ROS production and resistance to apoptosis. Int J Mol Med. 2016;38:1039-46.

56. Kelly RD, Sumer H, McKenzie M, Facucho-Oliveira J, Trounce IA, Verma PJ, St John JC. The effects of nuclear reprogramming on mitochondrial DNA replication. Stem Cell Rev. 2013;9:1-15.

57. Hance N, Ekstrand MI, Trifunovic A. Mitochondrial DNA polymerase gamma is essential for mammalian embryogenesis. Hum Mol Genet. 2005; 14:1775-83.

58. Sajadian SO, Tripura C, Samani FS, Ruoss M, Dooley S, Baharvand H, Nussler AK. Vitamin C enhances epigenetic modifications induced by 5-azacytidine and cell cycle arrest in the hepatocellular carcinoma cell lines HLE and Huh7. Clin Epigenetics. 2016;8:46.

59. Liu M, Ohtani H, Zhou W, Orskov AD, Charlet J, Zhang YW, Shen H, Baylin SB, Liang G, Gronbaek K, Jones PA. Vitamin C increases viral mimicry induced by 5-aza-2'-deoxycytidine. Proc Natl Acad Sci USA. 2016;113:10238-44

60. Berezovsky AD, Poisson LM, Cherba D, Webb CP, Transou AD, Lemke NW, Hong X, Hasselbach LA, Irtenkauf SM, Mikkelsen T, deCarvalho AC. Sox2 promotes malignancy in glioblastoma by regulating plasticity and astrocytic differentiation. Neoplasia. 2014;16:193-206, 206 e119-125.

61. Muona M, Berkovic SF, Dibbens LM, Oliver KL, Maljevic S, Bayly MA, Joensuu T, Canafoglia L, Franceschetti S, Michelucci R, et al. A recurrent de novo mutation in KCNC1 causes progressive myoclonus epilepsy. Nat Genet. 2015;47:39-46.

62. Aref-Eshghi E, Rodenhiser DI, Schenkel LC, Lin H, Skinner C, Ainsworth P, Pare G, Hood RL, Bulman DE, Kernohan KD, et al. Genomic DNA methylation signatures enable concurrent diagnosis and clinical genetic variant classification in neurodevelopmental syndromes. Am J Hum Genet. 2018;102:156-74

63. Hoischen A, Krumm N, Eichler EE. Prioritization of neurodevelopmental disease genes by discovery of new mutations. Nat Neurosci. 2014;17:764-72.

64. Reis K, Fransson A, Aspenstrom P. The Miro GTPases: at the heart of the mitochondrial transport machinery. FEBS Lett. 2009;583:1391-8.

65. Kay L, Pienaar IS, Cooray R, Black G, Soundararajan M. Understanding miro GTPases: implications in the treatment of neurodegenerative disorders. Mol Neurobiol. 2018;55:7352-65.

66. Lottaz C, Beier D, Meyer K, Kumar P, Hermann A, Schwarz J, Junker M, Oefner PJ, Bogdahn U, Wischhusen J, et al. Transcriptional profiles of CD133 + and CD133- glioblastoma-derived cancer stem cell lines suggest different cells of origin. Cancer Res. 2010;70:2030-40.

67. Campbell AM, Zagon IS, McLaughlin PJ. Astrocyte proliferation is regulated by the OGF-OGFr axis in vitro and in experimental autoimmune encephalomyelitis. Brain Res Bull. 2013;90:43-51.

68. Lee WT, Sun X, Tsai TS, Johnson JL, Gould JA, Garama DJ, Gough DJ, McKenzie M, Trounce IA, St John JC. Mitochondrial DNA haplotypes induce differential patterns of DNA methylation that result in differential chromosomal gene expression patterns. Cell Death Discov. 2017:3:17062.

69. Martin JL, Brown CE, Matthews-Davis N, Reardon JE. Effects of antiviral nucleoside analogs on human DNA polymerases and mitochondrial DNA synthesis. Antimicrob Agents Chemother. 1994;38:2743-9.

70. Weber M, Davies JJ, Wittig D, Oakeley EJ, Haase M, Lam WL, Schubeler D. Chromosome-wide and promoter-specific analyses identify sites of differential DNA methylation in normal and transformed human cells. Nat Genet. 2005;37:853-62.

71. Li H, Durbin R. Fast and accurate short read alignment with BurrowsWheeler transform. Bioinformatics. 2009:25:1754-60.

72. Yu G, Wang LG, He QY. ChIPseeker: an R/Bioconductor package for ChIP peak annotation, comparison and visualization. Bioinformatics. 2015;31:2382-3.

73. Khan A, Zhang X. dbSUPER: a database of super-enhancers in mouse and human genome. Nucleic Acids Res. 2016;44:D164-71.

74. ENCODE Project Consortium. The ENCODE (ENCyclopedia Of DNA Elements) Project. Science. 2004;306:636-40.

75. Mi H, Huang X, Muruganujan A, Tang H, Mills C, Kang D, Thomas PD. PANTHER version 11: expanded annotation data from Gene Ontology and Reactome pathways, and data analysis tool enhancements. Nucleic Acids Res. 2017:45:D183-9.

76. Chavez L, Jozefczuk J, Grimm C, Dietrich J, Timmermann B, Lehrach H, Herwig R, Adjaye J. Computational analysis of genome-wide DNA methylation during the differentiation of human embryonic stem cells along the endodermal lineage. Genome Res. 2010;20:1441-50.

77. Lienhard M, Grimm C, Morkel M, Herwig R, Chavez L. MEDIPS: genomewide differential coverage analysis of sequencing data derived from DNA enrichment experiments. Bioinformatics. 2014;30:284-6.

78. Quinlan AR, Hall IM. BEDTools: a flexible suite of utilities for comparing genomic features. Bioinformatics. 2010;26:841-2.

79. Quinlan AR. BEDTools: the Swiss-army tool for genome feature analysis. Curr Protoc Bioinform. 2014;47:11.12.1-34.

80. Ghosh S, Chan CK. Analysis of RNA-seq data using TopHat and cufflinks. Methods Mol Biol. 2016:1374:339-61. 